\title{
Chemotherapy-induced peripheral neuropathy: part 1—current state of knowledge and perspectives for pharmacotherapy
}

\author{
Kinga Sałat ${ }^{1}$
}

Received: 18 February 2020 / Revised: 20 April 2020 / Accepted: 28 April 2020 / Published online: 11 May 2020

(c) The Author(s) 2020

\section{Abstract}

Background Despite the increasing knowledge of the etiology of neuropathic pain, this type of chronic pain is resistant to available analgesics in approximately $50 \%$ of patients and therefore is continuously a subject of considerable interest for physiologists, neurologists, medicinal chemists, pharmacologists and others searching for more effective treatment options for this debilitating condition.

Materials and methods The present review article is the first of the two articles focused on chemotherapy-induced peripheral neuropathy (CIPN).

Results CIPN is regarded as one of the most common drug-induced neuropathies and is highly pharmacoresistant. The lack of efficacious pharmacological methods for treating CIPN and preventing its development makes CIPN-related neuropathic pain a serious therapeutic gap in current medicine and pharmacotherapy. In this paper, the most recent advances in the field of studies on CIPN caused by platinum compounds (namely oxaliplatin and cisplatin), taxanes, vinca alkaloids and bortezomib are summarized. Conclusions The prevalence of CIPN, potential causes, risk factors, symptoms and molecular mechanisms underlying this pharmacoresistant condition are discussed.

\section{Graphic abstract}

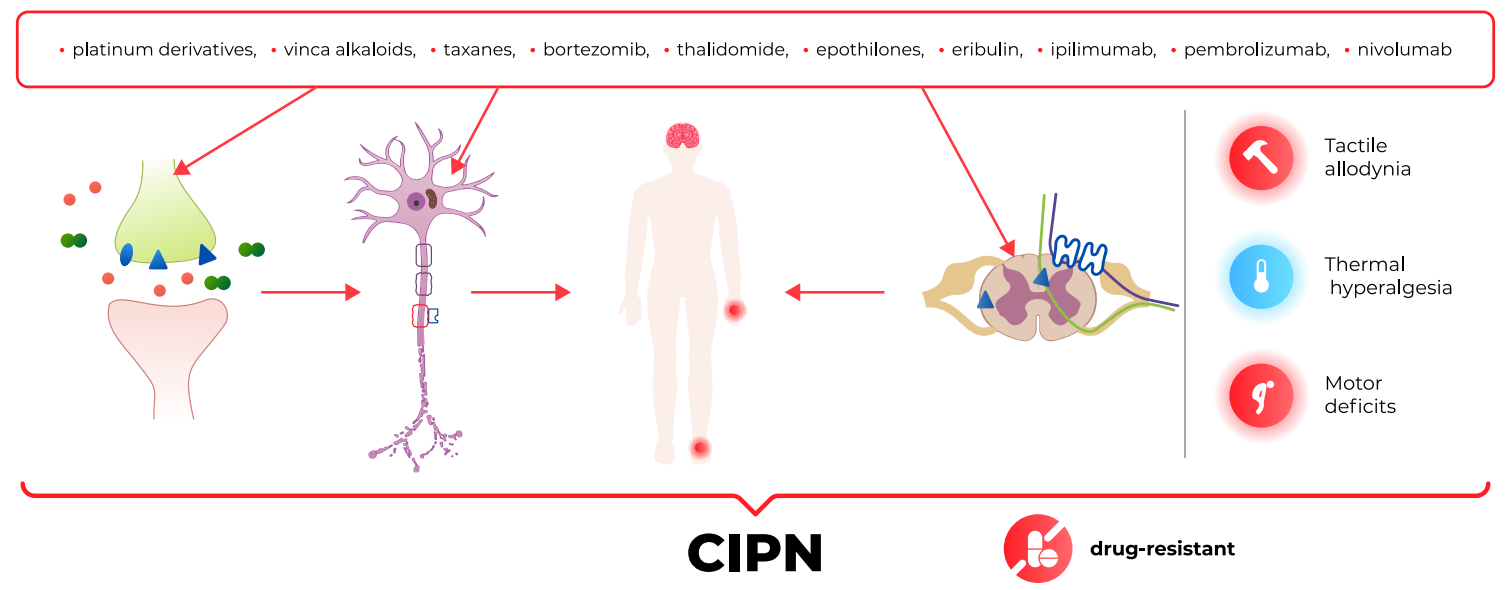

Keywords Chemotherapy-induced peripheral neuropathy $\cdot$ Neuronal hyperexcitability $\cdot$ Platinum derivatives $\cdot$ Paclitaxel . Vinca alkaloids · Bortezomib

Kinga Sałat

kinga.salat@uj.edu.pl

1 Department of Pharmacodynamics, Chair

of Pharmacodynamics, Jagiellonian University Medical

College, 9 Medyczna St., 30-688 Krakow, Poland 


\section{Introduction}

\section{Neuropathic pain as a major feature of neuropathy - General characteristics: Definition, epidemiology, symptoms and risk factors}

According to the International Association for the Study of Pain's 2011 definition, neuropathic pain is pain that arises as a direct consequence of a lesion or disease affecting the somatosensory system. This definition emphasizes the involvement and a key role of the somatosensory system in this clinical entity to distinguish it from other types of pain that may also be associated with disorders of the motor system [1].

Neuropathic pain is a chronic neurological disorder that represents a broad category of pain syndromes that include various peripheral and central nervous system impairments called neuropathies [2]. As a disease itself, neuropathic pain has a significantly negative impact on the sleep, everyday functioning and quality of life of patients. Therefore, it is also regarded as one of the triggering factors of anxiety and depression symptoms within the patient population [1].

A precise estimation of the incidence of neuropathic pain is difficult because of the lack of simple diagnostic criteria for large epidemiological surveys of the general population [1]. Epidemiological data estimate that the overall prevalence of neuropathic pain may be as high as $7-8 \%$, which corresponds to $20-25 \%$ of individuals with chronic pain. The values reported here may vary significantly for particular types of neuropathic pain, such as postherpetic neuralgia (8-10\%), painful diabetic neuropathy (14-26\%), and neuropathic pain related to surgery (10-50\%), multiple sclerosis (20-30\%), spinal cord injury (30-40\%) and cancer (17-19\%) [3].

Clinically, neuropathic pain is characterized by socalled positive and negative symptoms. Positive symptoms include various painful symptoms (tactile and thermal allodynia or hyperalgesia and spontaneous pain episodes), paresthesias, and dysesthesia (e.g., tingling, prickling, burning, knifelike, electrical, pulling or tightening sensations). Negative symptoms usually include neurological sensory deficits (numbness and the feeling of wearing socks all the time) in the painful area and are frequently accompanied by other deficits, such as motor or cognitive impairments [3-5].

Neuropathic pain is regarded as a heterogeneous and multidimensional clinical entity. For example, peripheral neuropathic pain comprises postherpetic neuralgia and traumatic nerve injury, but it should be noted that many of these patients may suffer from mixed pain syndromes involving both neuropathic and nonneuropathic components (e.g., lumbar or cervical radiculopathies). Central neuropathic pain syndromes are also common, being observed in up to $8 \%$ of stroke patients, 30-50\% of patients with a spinal cord injury and up to $20-25 \%$ of patients with multiple sclerosis or Parkinson's disease. Thus, neuropathic pain patients with distinct sensory profiles may respond differently to available treatment options.

In recent years, several risk factors for neuropathy and neuropathic pain, including age $>60$ years, female sex, participation in manual labor $[3,6,7]$, and smoking history $[8,9]$ have been identified, and the number of potential causes of neuropathic pain is still increasing (Fig. 1). These causes include metabolic (diabetic), infectious (varicella zoster and human immunodeficiency virus infections and Mycobacterium leprae), traumatic, immune (Guillain-Barre syndrome), inherited (e.g., inherited erythromelalgia caused by mutations in SCN9A, which encodes the voltage-gated sodium channel $\mathrm{Na}_{\mathrm{v}} 1.7$ ) and drug-induced factors [1].

Despite the increasing knowledge of the etiology of neuropathic pain, this type of chronic pain is resistant to available analgesics in approximately $50 \%$ of patients $[2,10]$ and, therefore, is continuously a subject of considerable interest for physiologists, neurologists, medicinal chemists, pharmacologists and others searching for more effective treatment options for this debilitating condition.

The present review article is the first of two articles focused on chemotherapy-induced peripheral neuropathy (CIPN), which is one of the most common drug-induced neuropathies and is highly pharmacoresistant.

\section{CIPN-Definition and causes}

Epidemiological data presented by the World Health Organization indicate that cancer is the second leading cause of death worldwide following heart disease. It was responsible for approximately 9.6 million deaths in 2018, and the high mortality rate of cancer makes it a civilizational disease often termed as 'a cancer epidemic' $[11,12]$.

In the last decades, innovative systemic anticancer therapies have been used more broadly [13]. This, together with progress in the early detection of tumors and the high success rate of cancer treatment, has increased the number of cancer survivors. On the other hand, with the growing use of antitumor drugs, the prevalence of serious adverse iatrogenic effects caused by antitumor drugs have become a significant clinical issue in the cancer patient population [14].

CIPN is one of the most common dose-limiting adverse effects of many chemotherapeutic agents, such as platinum derivatives, taxanes, vinca alkaloids, thalidomide, epothilones, eribulin, ipilimumab, pembrolizumab, 


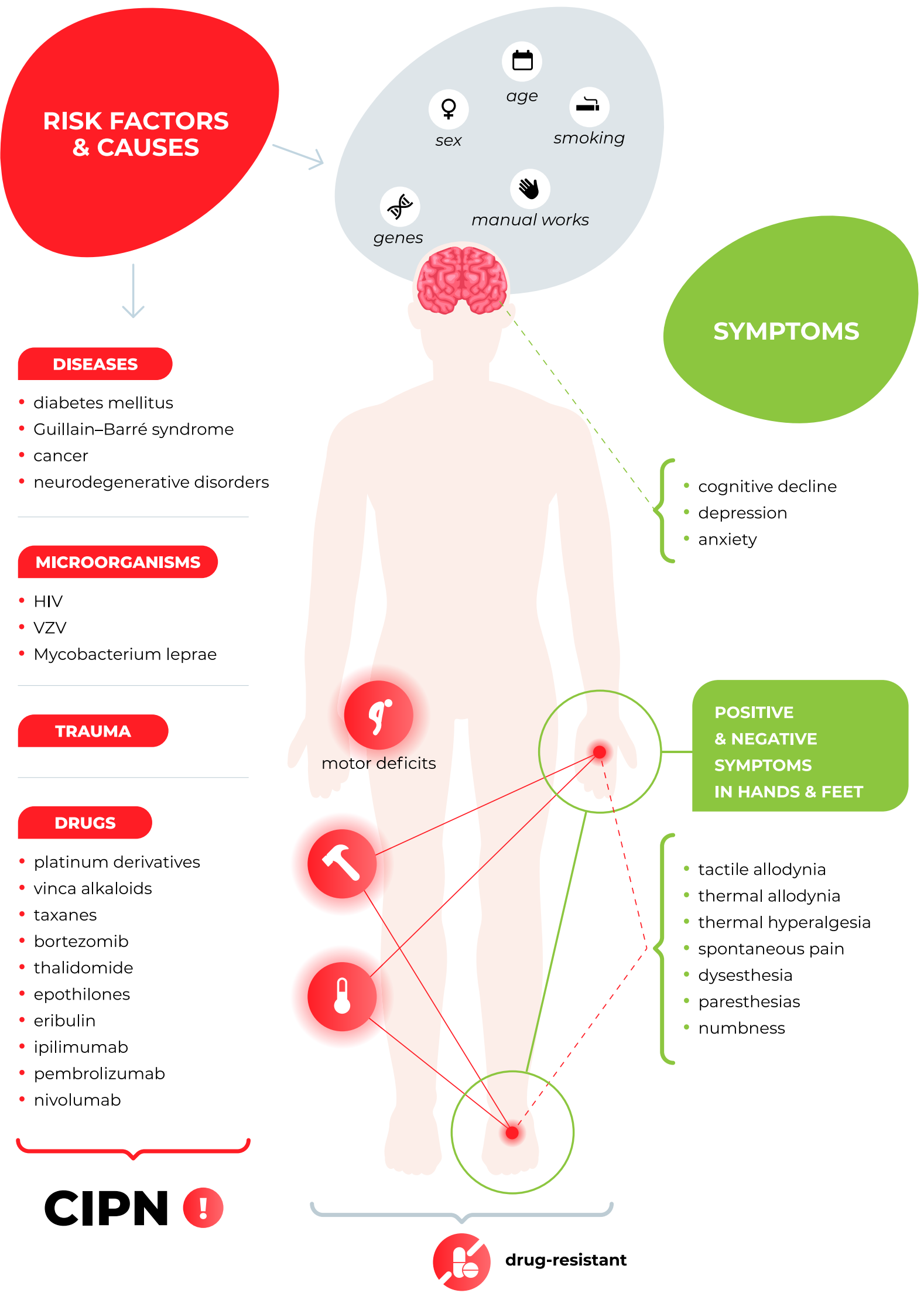

Fig. 1 Neuropathy-Causes, risk factors and symptoms 


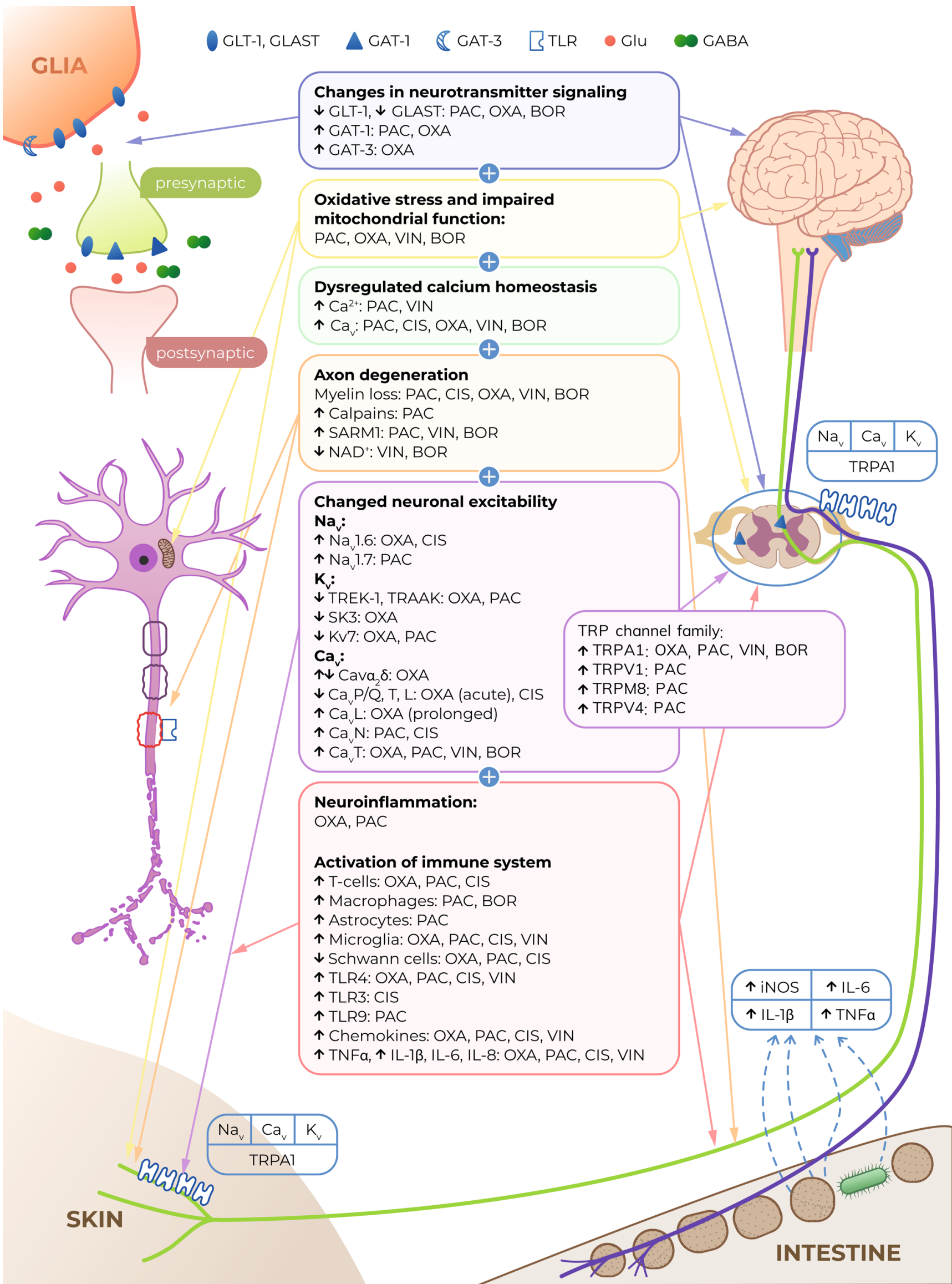


4Fig. 2 Antitumor drugs that induce CIPN and the main mechanisms underlying CIPN [18-21]. GLT-1 glutamate transporter 1, GLAST GLutamate and ASpartate Transporter, GABA $\gamma$-aminobutyric acid, GAT GABA transporter, TLR toll-like receptor, Glu glutamate, PAC paclitaxel, VIN vincristine, $O X A$ oxaliplatin, $C I S$ cisplatin, $B O R$ bortezomib, $N a_{v}$ voltage-gated sodium channels, $C a_{v}$ voltage-gated calcium channels, $K_{v}$ voltage-gated potassium channels, TRPA1 Transient Receptor Potential Ankyrin-repeat 1 channel, TRPV Transient Receptor Potential Vanilloid channel, TRPM8 Transient Receptor Potential Melastatin 8 channel, iNOS inducible nitric oxide synthase, $I L$ interleukin, TNF $\alpha$ tumor necrosis factor $\alpha, S A R M 1$ sterile alpha and TIR motif-containing protein $1, N A D+$ nicotinamide adenine dinucleotide

nivolumab and bortezomib (Figs. 1, 2). It affects $>60 \%$ of patients receiving anticancer therapy. Although CIPN is a nonfatal condition, it significantly worsens patients' quality of life and is usually regarded as very troublesome, as it might not only influence the efficacy of antitumor agents but also be a major cause of ongoing pain in cancer survivors [15-17].

At present, CIPN is often considered an unavoidable adverse effect of cancer chemotherapy that should be accepted by cancer patients and clinicians in the light of the extended life-span offered by these drugs. Since the major manifestation of CIPN comprises severe pain episodes involving tactile and thermal allodynia, hyperalgesia and spontaneous pain, analgesic drugs are used in patients exposed to CIPN-inducing antitumor therapy. However, it should be noted that the analgesic drugs that effectively relieve pain symptoms in CIPN and are used as interventional treatments for pre-existing CIPN-related pain are very limited and that their efficacy in CIPN is significantly lower than that observed in other neuropathic pain types. Importantly, there are currently no recommended options for effectively preventing neuropathic pain in CIPN [19], and strong evidence for the utility and clinical efficacy of some previously tested preventive therapies (e.g., pregabalin, gabapentin, duloxetine, calcium/magnesium infusion, amifostine, glutathione, glutamine, acetyl-L-carnitine and erythropoietin) is still limited [22]. The lack of efficacious pharmacological methods for treating CIPN and preventing its development [23] makes CIPN-related neuropathic pain a serious therapeutic gap in current medicine and pharmacotherapy. So far, there has been only one potential drug candidate for preventing the development of oxaliplatininduced acute and delayed CIPN, namely, calmangafodipir, a mitochondrial manganese superoxide dismutase mimetic, which is currently being studied in a placebo-controlled, double-blinded randomized phase III study [24]. Therefore, basic science research in this area and large clinical trials are urgently needed to establish novel and effective therapeutic solutions to prevent this devastating condition [17]. There seems to be a strong demand for a more thorough understanding of the etiology of CIPN, which would help to develop effective mechanism-based disease-modifying therapies. Importantly, such approaches should not negatively influence the antitumor effects of the chemotherapeutics used [19, 23].

Only few studies have been conducted to compare directly the characteristics of CIPN and other neuropathies. As mentioned above, these studies have shown that neuropathic pain in the course of CIPN is more pharmacoresistant than other neuropathic pain types but, on the other hand, some common mechanistic features have also been shown. Importantly, in a manner similar to other peripheral neuropathies, in CIPN the central nervous system is affected due to the changes in the barrage of peripheral input (discussed in "Central nervous system structures and neurotransmitters"). Therefore, many analgesic drugs used for alleviating CIPN-related neuropathic pain are also used in neuropathic pain of other origin.

A direct comparison between diabetic neuropathy and CIPN has been conducted by Jin and colleagues [25] with respect to symptom severity and therapeutic responses. Using a rat model, they compared peripheral nerve damage due to hyperglycemia (i.e., painful diabetic neuropathy) with that caused by paclitaxel treatment. Biochemical, sensory and immunohistochemical parameters of cutaneous and sciatic nerves and the therapeutic effects of test drugs (alpha-lipoic acid and DA-9801) were compared in these two models. Sensory thresholds of animals to mechanical, heat, and pressure stimuli were altered by both hyperglycemia and paclitaxel when compared with controls. There were no significant differences in the biochemical markers of blood glutathione between diabetic rats and the paclitaxel-treated group. Quantitative comparisons of peripheral nerves by intraepidermal nerve fiber density analysis indicated that both groups were similar, but nerve density was significantly improved after alpha-lipoic acid and DA-9801 treatment in diabetic animals but not in the paclitaxel-treated groups. Sciatic nerves were less damaged in the paclitaxel-treated groups compared with the diabetic group. Hence, it was concluded that the manifestation of neuropathy, as well as some therapeutic responses in CIPN may be different from those observed in other peripheral neuropathies.

Similarity between paclitaxel-induced CIPN model and short-term models of traumatic neuropathy has also been demonstrated [26].

\section{Prevalence of CIPN and risk factors}

As mentioned above, the survival rates of patients treated with antitumor agents are increasing. Hence, CIPN and CIPN-related neuropathic pain episodes have become a significant clinical issue among cancer survivors [15]. In general, the prevalence of CIPN resulting from different antitumor drugs and doses varies significantly, with reported prevalence rates ranging from 19 to more 
than $85 \%$ [17]. It is estimated that approximately $70 \%$ of patients receiving chemotherapy develop CIPN during the first month of treatment $[17,20]$, whereas in approximately $20-30 \%$ of these patients, CIPN might be converted to a chronic, persistent and highly pharmacoresistant form $[17,23]$ that can be observed 6 months or even longer after therapy cessation [14, 16, 27, 28]. Importantly, the symptoms of these delayed complications may persist for several months and can be progressively aggravated; this phenomenon in which either mild neuropathy worsens or a new form of CIPN develops is termed 'coasting' [21]. Since chemotherapeutics are not being applied when this disorder develops, coasting is a great challenge for clinicians; patients may be cancer-free but suffer from neuropathy evoked by previously received anticancer treatment [17].

Importantly, CIPN tends to occur both in adults and in younger patients. In children, most cases of CIPN are due to the use of vincristine and platinum derivatives, as other CIPN-inducing chemotherapeutics are not routinely used in this population [15]. It should also be noted that the prevalence and symptoms of CIPN seem to be age-related. This is thought to result from the distinct neurobiology of the peripheral nervous system in children and adults. The diameter, density and myelination of axons in the dorsal root ganglion significantly change during childhood to achieve full maturation, and this may have a strong influence on the risk of development and severity of CIPN. This notion is supported by previous observations that vincristine causes motor deficits more frequently in pediatric patients than adults. The reason for this seems to be unclear, and several potential mechanisms, including the use of higher doses, altered pharmacokinetics, different neuronal biology, and the lack of early detection of neurotoxic symptoms, should be considered [15]. The treatment of CIPN symptoms, recovery, and the delayed effects of chemotherapy may also vary between adult and pediatric populations. Importantly, drugs commonly used to treat neuropathic pain in adult patients (e.g., duloxetine) have not been widely studied in children. Also, physical and exercise-based therapies have not been evaluated in children receiving CIPN-inducing drugs. Thus, both the symptoms of CIPN and methods for alleviating them might be different between these two populations [15].

In addition to age, a number of other potential risk factors for CIPN development have been identified. These include the cumulative dose of a chemotherapeutic agent, genetic factors, a history of neuropathy before the start of chemotherapy (e.g., painful diabetic neuropathy or neuropathy due to viral infections), impaired renal function with reduced creatinine clearance, and smoking history $[9,15,17,28-32]$.

\section{Symptoms of CIPN}

Within the patient population, numerous symptoms of CIPN have been identified, all of which seriously worsening patients' quality of life [14]. It has been widely reported that patients who develop CIPN symptoms have significant difficulties in essential daily functioning. In these patients, unsteady gait (numbness and the loss of joint position sense), difficulties in fine finger movements, pain during walking (mechanical allodynia), and cold-exacerbated pain episodes (cold hypersensitivity) have been reported [17].

In general, the characteristics, time of onset and duration of CIPN symptoms depend on the chemotherapeutic agent used. Most frequently these symptoms appear after repeated (three to four) cycles of therapy; however, the immediate manifestation of CIPN symptoms has also been noted and in some patients, these symptoms might become permanent and continue for years ('coasting') [33, 34].

CIPN is a disease with a plethora of symptoms associated with distress (mood disorders: anxiety, depression [35], sleep disorders [36], cognitive impairments (chemobrain, a.k.a. chemofog $[37,38])$, fatigue, altered taste sensation, and nausea), and a wide range of neurological symptoms present mainly in the hands and feet (e.g., numbness, tingling, pain, muscle weakness and sensitivity to cold or heat) are also observed [14, 29, 39]. These symptoms can be classified as a motor or sensory impairments. These impairments typically include sensory axonal peripheral neuropathy ('stocking and glove' neuropathy), which is accompanied by numbness, paresthesias, ongoing/spontaneous pain hypersensitivity to mechanical and thermal stimuli in the hands and feet [17], and motor symptoms such as distal weakness, reduced or absent Achilles tendon reflexes, paresthesias, breath dysregulation, abnormal swallowing, laryngospasm, muscle cramps, jaw stiffness, visual field changes, muscle weakness, reduced balance control and insecure gait, the mechanisms of which are not fully understood [20, 33, 40, 41].

\section{Molecular basis of CIPN}

The mechanisms of action through which antitumor drugs induce cell death and inhibit cell proliferation are diverse but very well defined. It is, however, not entirely clear, if these effects are also responsible for the damage to nonproliferating sensory neurons that underlies CIPN development. Available data from basic science studies indicate that in addition to direct cytotoxic effects, other cell-type-specific actions resulting from the on-target pharmacological effects of CIPN-inducing antitumor drugs might also contribute to the development of CIPN and decreased viability of sensory neurons. In addition, off-target effects may also be implicated in CIPN development, but this issue requires 
further and more detailed research [20]. Therefore, CIPN is regarded a multifactorial disorder with diverse pharmacological mechanisms, and a number of common pathologies, including altered ion channel functions, oxidative stress, axonal degeneration, impaired calcium homeostasis, neuroinflammation, and activation of the immune system, have been proposed to underlie CIPN development (Fig. 2).

\section{Oxidative stress}

In addition to controlling cellular energy production and energy supply, mitochondria are also involved in the regulation of cell death. Neuronal mitochondrial dysfunction resulting in nitro-oxidative stress [42] is regarded as one of the most important contributors to CIPN development $[23,29,43]$.

Several antitumor drugs, including oxaliplatin, cause damage to neuronal and nonneuronal mitochondria, thus leading to oxidative stress mediated by redox-sensitive TRPA1 channels. These are biomolecules that are also implicated in oxaliplatin-induced mechanical and cold hypersensitivity [44-50]. Oxidative stress increases the production of proinflammatory mediators, which further destroy mitochondria, enhance the production of reactive oxygen species and contribute to various pathological processes resulting from oxidative stress. These phenomena might also cause demyelination and disruption of the cytoskeleton of peripheral nerves [51].

Oxaliplatin has been shown to bind to mitochondrial DNA and form adducts that cannot be repaired due to the lack of DNA repair systems within mitochondria. These adducts impair mitochondrial DNA replication and transcription, leading to altered protein synthesis and impaired respiratory chain function. In addition, vincristine dysregulates neuronal mitochondria, which leads to altered neuronal excitability and glial cell dysfunction. The influence of vincristine on mitochondria is thought to involve altered mitochondrial calcium signaling, and the maintenance of intracellular calcium homeostasis is beneficial for preventing CIPN [51, 52]. Paclitaxel does not directly affect mitochondrial DNA but induces swollen and vacuolated mitochondria in both myelinated and unmyelinated sensory axons, and these changes are accompanied by increased production of reactive oxygen species in the nervous system [20,53-55].

The effect of the CIPN-inducing proteasome inhibitor bortezomib on mitochondria in sensory neurons has also been investigated [56]. In a previous study bortezomib was shown to alter the metabolic phenotype of sensory neurons and increase the production of metabolites due to aerobic glycolysis, thus resulting in CIPN development. It was also demonstrated that the targeted inhibition of the enzymes that maintain aerobic glycolysis might be a strategy for treating CIPN.

\section{Dysregulated calcium homeostasis}

Impaired calcium homeostasis and calcium signaling have also been shown to contribute to the development of oxaliplatin-, cisplatin-, vincristine-, and paclitaxel-induced CIPN. This calcium-dependent neurotoxic pathway is particularly important for oxaliplatin, of which oxalate, a well-known calcium chelator that contributes to the development of oxaliplatin-induced acute form of CIPN, is a metabolite.

Unlike that of oxaliplatin-induced neuropathy, the contribution of calcium ions to cisplatin-induced neuropathy is relatively poorly understood. Cisplatin increases the expression of N-type voltage-gated calcium channels $\left(\mathrm{Ca}_{\mathrm{v}} 2.2\right)$ [57, 58], but the role of these channels in the clinical manifestation of cisplatin-induced CIPN remains unclear. Calcium signaling has also been reported to participate in CIPN induced by paclitaxel [55], which causes rapid mitochondrial depolarization and calcium release in both neuronal and nonneuronal cells, possibly via the activation of the mitochondrial permeability transition pore $[55,59]$.

Increased expression of low-voltage-activated calcium channels (T-type channels; $\mathrm{Ca}_{\mathrm{v}} 3.2$ ) has also been shown in paclitaxel-exposed rat dorsal root ganglia. T-type current amplitudes are increased 7 days after paclitaxel treatment [60].

Maintaining intracellular calcium homeostasis attenuates CIPN caused by vincristine [52].

Increased protein levels of $\mathrm{Ca}_{\mathrm{v}} 3.2$ in primary afferents caused by decreased proteasomal degradation of $\mathrm{Ca}_{\mathrm{v}} 3.2$ (T-type) channels is involved in bortezomib-induced neuropathic pain [61].

\section{Axonal degeneration}

Animal and human studies have demonstrated that the longterm use of the platinum derivatives [62, 63] paclitaxel [64], vincristine [65], and bortezomib [66] can induce axonal degeneration, specifically, the loss of large myelinated, small unmyelinated and intra-epidermal nerve fibers. The loss of myelin and changes to the axonal cytoskeleton may alter the structure and impair the function of peripheral nerves, thus leading to the development of sensory and motor peripheral neuropathy and altered pain perception. The molecular mechanisms of these phenomena are not fully established $[43,63,67]$.

In patients, oxaliplatin causes moderate axonal degeneration and the loss of intra-epidermal nerve fibers, while cisplatin induces axonal degeneration of large myelinated fibers and myelin disruption. Similar pathologies have also been noted within myelinated fibers of the sciatic nerve in cisplatin-treated mice [33, 68]. 
The degeneration of distal sensory axons, demyelination and nerve fiber loss have also been observed in vincristine-, bortezomib-, and paclitaxel-induced neuropathy $[20,69]$.

A zebrafish model has been used to study the mechanisms underlying paclitaxel-induced neurotoxicity, sensory axon degeneration and the loss of touch response in the distal caudal fin. In zebrafish larvae, paclitaxel induces epithelial damage and reduces the mechanical stress resistance of the skin prior to the induction of axonal degeneration. Reduced healing capacity of the injured skin of paclitaxeltreated zebrafish and scratch-wounded HEK001 human keratinocytes has also been demonstrated. The results of this research demonstrated that paclitaxel induces the upregulation of matrix-metalloproteinase 13 in the skin and promotes epithelial damage that precedes axonal degeneration [70].

In CIPN, calpains, as calcium-dependent proteases, have been shown to contribute to axonal degeneration [69]. Paclitaxel induces CIPN by altering inositol trisphosphate $\left(\mathrm{IP}_{3}\right)$ receptor phosphorylation and intracellular calcium flux. It also activates calpain proteases [71].

Recent studies have also identified a new molecular mechanism involving sterile alpha and TIR motif-containing protein 1 (SARM1) as an injury-inducible NADase that triggers axonal loss $[9,67]$. The activation of SARM1 has been shown to contribute to Wallerian degeneration, a phenomenon that occurs during axonal degeneration [72]. The genetic deletion of SARM1 protects axons from degeneration after axotomy in mice. Turkiew and colleagues showed that paclitaxel-induced CIPN model mice lacking the Sarm1 gene are resistant to distal axonal degeneration [64].

Subacute/chronic axonal loss induced by vincristine also involves the SARM1-mediated axonal destruction pathway, and the genetic deletion of SARM1 blocks the development of bortezomib- and vincristine-induced CIPN in mice [65, 72].

The induction of CIPN by axonal degeneration is thought to be due to a loss of nicotinamide adenine dinucleotide $(\mathrm{NAD}+)$ via the SARM1 pathway [73]. Using cultured neurons, Geisler and colleagues found that vincristine and bortezomib are able to induce an axonal degeneration program that involves the nicotinamide mononucleotide NMNAT2, SARM1, and the loss of NAD +. Both drugs activate SARM1 and cause the SARM1-dependent depletion of axonal NAD + , which is followed by local metabolic collapse, axonal fragmentation and axonal degeneration. Of note, the actions of vincristine and bortezomib involve different mechanisms, i.e., Wallerian degeneration occurs after vincristine administration, while bortezomib induces apoptosis [72].

It has also been suggested that vincristine might be responsible for an excessive increase in a NAD + direct precursor, i.e., a nicotinamide mononucleotide, rather than a decreased level of NAD + and that this is also likely to play a role in CIPN development [73].

\section{Changes in neuronal excitability}

Altered peripheral nerve excitability has also been implicated in CIPN development. The altered expression and functional impairment of voltage-gated sodium $\left(\mathrm{Na}_{\mathrm{v}}\right)$, voltage-gated potassium $\left(\mathrm{K}_{\mathrm{v}}\right)$, voltage-gated calcium $\left(\mathrm{Ca}_{\mathrm{v}}\right)$ and transient receptor potential family (TRP) channels are regarded as the most prominent phenomena underlying CIPN caused by the platinum derivatives vincristine, paclitaxel and bortezomib [17, 74].

$\mathrm{Na}_{\mathrm{v}}$ channels $\mathrm{Na}_{\mathrm{v}} 1.6$ channels appear to be involved in the development of oxaliplatin-induced cold hyperalgesia [75], and the acute oxaliplatin-induced aggravation of cold hypersensitivity is abolished by the administration of a selective $\mathrm{Na}_{\mathrm{v}} 1.6$ inhibitor [76]. Our recent study also demonstrated that ambroxol, a $\mathrm{Na}_{\mathrm{v}}$ channel inhibitor, alone or in combination with pregabalin efficiently attenuates cold allodynia in oxaliplatin-treated mice; this suggested that $\mathrm{Na}_{\mathrm{v}}$ channels participate in this phenomenon [77]. The acute neurotoxicity caused by oxaliplatin is thought to be due to the accumulation of its metabolite oxalate, which is a calcium chelator. It immobilizes calcium ions and alters calcium-sensitive $\mathrm{Na}_{\mathrm{v}}$ channel kinetics [78].

Clinically, the role of $\mathrm{Na}_{\mathrm{v}}$ channels in CIPN development was also confirmed in a cisplatin-treated patient in whom lacosamide, an antagonist of $\mathrm{Na}_{\mathrm{v}}$ channels, significantly alleviated the severe painful symptoms of CIPN [79]. However, it should be noted that in addition to $\mathrm{Na}_{\mathrm{v}}$ channels, other mechanisms have been implicated in cisplatin- and carboplatin-induced CIPN. Avan and colleagues demonstrated that both these drugs are neurotoxic because they induce DNA adduct accumulation and the inhibition of DNA repair pathways, such as the extracellular signal-regulated kinase $1 / 2$, c-Jun N-terminal kinase/stress-activated protein kinase, and p38 mitogen-activated protein kinase pathways, which ultimately results in apoptosis [78].

The gene expression and currents of $\mathrm{Na}_{\mathrm{v}} 1.7$ channel $\left(\mathrm{Na}_{\mathrm{v}} 1.7\right)$ are increased in the dorsal root ganglia of paclitaxel-treated rats. Similarly, gain-of-function mutations in human $\mathrm{Na}_{\mathrm{v}} 1.7$ channels have also been noted in paclitaxeltreated patients $[80,81]$.

$\mathrm{K}_{\mathrm{v}}$ channels $\mathrm{In}$ isolated rat sciatic nerves, oxaliplatin causes broadening of the repolarization phase, induced repetitive firing and afterhyperpolarization, and these effects are caused by its effect on $\mathrm{K}_{\mathrm{v}}$ channels. After oxaliplatin and paclitaxel treatment, decreased expression of two-pore domain $\mathrm{K}^{+}$channels (TREK-1 and TRAAK) is observed in the rodent dorsal root ganglia [20]. In mice, riluzole, an 
activator of TREK-1 and TRAAK, prevents both sensory and motor deficits induced by oxaliplatin and attenuates the depression-like symptoms induced by oxaliplatin. Riluzole has no negative effect on the antiproliferative capacity of oxaliplatin in human colorectal cancer cells and does not reduce its anticancer effect in a mouse model of colorectal cancer. Moreover, riluzole decreases the viability of a human colorectal cancer cell line in vitro and inhibits polyp development in vivo. These data confirm the important role of TREK-1 and TRAAK in CIPN [82, 83].

A potential role for the potassium channel SK3 $(\mathrm{KCNN} 3$ gene) in oxaliplatin-induced CIPN has also been suggested. In a preclinical model, a slight association between CIPN and $\mathrm{CAG}$ repeat polymorphisms in the KCNN3 gene was shown, but such an association between CIPN and KCNN3 polymorphisms was not shown in patients [84]. In a mouse study, the activation of $\mathrm{K}_{\mathrm{v}} 7$ channels reduced the symptoms of CIPN induced by oxaliplatin and paclitaxel [85]. In line with this, minoxidil, a potassium channel opener alleviates the signs of paclitaxel-related CIPN [17].

$\mathrm{Ca}_{\mathrm{v}}$ channels Increased expression of $\mathrm{Ca}_{\mathrm{v}} \alpha_{2} \delta-1$ subunit mRNA and protein in the spinal cord 2 and 4 days after oxaliplatin treatment contributes to acute cold hypersensitivity in rodents [86]. A crucial role of the $\mathrm{Ca}_{\mathrm{v}} \alpha_{2} \delta-1$ subunit in the development of oxaliplatin-induced acute and delayed cold hypersensitivity has been shown in mice [77] and rats [86].

The short- and long-term effects of the exposure of $\mathrm{Ca}_{\mathrm{v}}$ channels to oxaliplatin have been investigated in rat small dorsal root ganglia. $\mathrm{Ca}_{\mathrm{v}}$ channel currents are concentrationdependently reduced by oxaliplatin. Moreover, differential time-dependent effects of oxaliplatin on calcium currents have been noted. Acute treatment with oxaliplatin leads to a reduction in P/Q-, T-, and L-type $\mathrm{Ca}_{\mathrm{v}}$ channel currents, while there is no effect of this acute treatment on N-type $\mathrm{Ca}_{\mathrm{v}}$ channel currents. In contrast to this, prolonged $(24 \mathrm{~h})$ exposure of dorsal root ganglia neurons to oxaliplatin significantly increases L- and T-type $\mathrm{Ca}_{\mathrm{v}}$ channel currents. Increased L- and T-type $\mathrm{Ca}_{\mathrm{v}}$ channel protein levels in dorsal root ganglion neurons have also been noted $24 \mathrm{~h}$ after oxaliplatin exposure [87]. Analogous research showing a crucial role of N-type $\mathrm{Ca}_{\mathrm{v}}$ channels in cisplatin-induced polyneuropathy was conducted. This study showed that cisplatin reduced $\mathrm{Ca}_{\mathrm{v}}$ channel currents in a concentration-dependent manner. Subtype-specific measurements of $\mathrm{Ca}_{\mathrm{v}}$ channel currents showed the differential effects of this platinum derivative on $\mathrm{Ca}_{\mathrm{v}}$ channel subtypes. While the currents of P/Q-, $\mathrm{L}$ - and T-type $\mathrm{Ca}_{\mathrm{v}}$ channels were reduced, those of $\mathrm{N}$-type $\mathrm{Ca}_{\mathrm{v}}$ channels were increased. Further analyses revealed an increase in $\mathrm{N}$-type $\mathrm{Ca}_{\mathrm{v}}$ channel protein levels in dorsal root ganglion neurons $24 \mathrm{~h}$ after cisplatin administration. Cisplatin activated caspase- 3 and this effect were prevented by $\omega$-conotoxin MVIIA, an $\mathrm{N}$-type $\mathrm{Ca}_{\mathrm{v}}$ channel inhibitor [58].
A recent study [88] showed that cisplatin-induced neurotoxicity might be due to functional alterations in $\mathrm{Ca}_{\mathrm{v}}$ channels but not to structural damage to these channels, as no morphological signs of damage, apoptosis or necrosis were noted in dorsal root ganglion cells exposed to cisplatin for 26 days.

Increased levels of $\mathrm{Ca}_{\mathrm{v}}$ channel mRNA within dorsal root ganglion neurons have been demonstrated in paclitaxeltreated mice, and $\mathrm{Ca}_{\mathrm{v}}$ channel antagonists (gabapentin and ethosuximide) effectively reduce hyperalgesia in rodents with paclitaxel- and vincristine-induced CIPN [17]. Many studies have confirmed a crucial role of $\mathrm{N}$-type and T-type $\mathrm{Ca}_{\mathrm{v}}$ channels in paclitaxel-induced CIPN [74] as well as a key role of T-type $\mathrm{Ca}_{\mathrm{v}}$ channels in CIPN caused by vincristine [89].

A mouse study showed that the inhibition of the proteasomal degradation of T-type $\mathrm{Ca}_{\mathrm{v}}$ channels by bortezomib and bortezomib-induced increases in the levels of USP5, a deubiquitinating enzyme that specifically inhibits the proteasomal degradation of $\mathrm{T}$-type $\mathrm{Ca}_{\mathrm{v}}$ channels, increases the protein levels of T-type $\mathrm{Ca}_{\mathrm{v}}$ channels in nociceptors. The systemic administration of T-type calcium channel blockers reverses CIPN caused by bortezomib. Also in ND7/23 cells, bortezomib increases the protein levels of T-type $\mathrm{Ca}_{\mathrm{v}}$ channels and T-channel-dependent currents [61].

TRP channels Altered expression and function of several thermo- and mechanosensitive Transient Receptor Potential (TRP) channels, namely, vanilloid 1 (TRPV1), Ankyrinrepeat 1 (TRPA1), and melastatin 8 (TRPM8) [43, 46, 47, 90, 91], and TRPA1- and TRPV4-dependent oxidative stress have also been reported in CIPN [47, 92-95].

In mice, oxaliplatin-induced rapid-onset cold hypersensitivity is ameliorated by TRPA1 blockade $[49,96]$. Oxaliplatin stimulates TRPA1 but does no effect on TRPM8 or TRPV1 channels either in vivo or in vitro. These responses are caused by the oxaliplatin metabolite-oxalate. In human TRPA1-expressing cells, oxaliplatin and oxalate cause TRPA1 sensitization to reactive oxygen species (ROS) by inhibiting prolyl hydroxylases, which is consistent with the observed cold hypersensitivity. Hence, it is thought that oxaliplatin-induced acute cold hypersensitivity is caused by TRPA1 sensitization to ROS via enzyme inhibition, which enables TRPA1 to convert ROS signals into cold sensitivity [47, 96].

Oxaliplatin-induced TRPA1 activation occurs via a glutathione-sensitive mechanism [94, 96]. In a study by Miyake and colleagues, a high concentration of oxaliplatin increased intracellular calcium concentration in human (h) TRPA1-expressing HEK293 cells. Oxaliplatin also induced the rapid generation of hydrogen peroxide and evoked ROSmediated cysteine oxidation-dependent hTRPA1 activation. The observed calcium influx was prevented in the presence 
of glutathione. In contrast to this, a lower concentration of oxaliplatin $(100 \mu \mathrm{M})$ did not increase the intracellular calcium concentration but caused the cold-induced cysteine oxidation-dependent opening of human TRPA1 channels. These concentration-dependent biochemical mechanisms of the observed phenomena were different [96].

Paclitaxel activates and sensitizes the function of TRPV1 and TRPV1 antagonists induced analgesia in paclitaxelrelated CIPN [17]. TRPA1 and TRPM8 channels have also been implicated in paclitaxel-induced neurotoxicity and CIPN-related pain behavior in mice [97]. A recent study also confirmed a role of TRPV4 channels in CIPN caused by paclitaxel. In this study [93], the administration of paclitaxel resulted in strong $\mathrm{IP}_{3}$-mediated calcium signals amplified by calcium entry through TRPV4 channels. Blocking calcium influx through TRPV4 channels reduced cell death in cultured dorsal root ganglia neurons, and the pretreatment of mice with the TRPV4 inhibitor (HC067047) prior to paclitaxel injection prevented both the neurotoxic effects of paclitaxel on electrophysiology and behavior [93].

The exposure of isolated sensory neurons to vinca alkaloids produces an inward sodium current that depolarizes these neurons, resulting in neuronal firing. These neuronal effects are regulated by TRPA 1 channels, and hypersensitivity to painful stimuli in response to vinca alkaloid administration is reduced in TrpA1 mutant flies and mice [98].

TRPA1 channels are also involved in bortezomib-induced neurotoxicity, and the selective blockade of these channels by Ph $\alpha 1 \beta$ (a peptide from the venom of the armed spider Phoneutria nigriventer) and CTK 01512-2 (a recombinant form of the peptide) reduces the TRPA1-dependent neuropathic pain-like responses induced by bortezomib [99].

\section{Activation of the immune system and neuroinflammation}

Antitumor drugs modulate the immune system, and this constitutes one of the most important mechanisms underlying tumor cell destruction. Simultaneously, the activation of the immune system, the recruitment of immune cells and neuroinflammation are regarded as a potential significant contributors to the development of CIPN [17, 100-104].

An increase in the peripheral levels of proinflammatory cytokines, changes in immune signaling pathways and a strong correlation between inflammation and peripheral neuropathy caused by chemotherapy have been observed in numerous studies [102, 105, 106].

It was recently shown that vincristine dysregulates genes associated with immunological processes, whereas oxaliplatin causes the dysregulation of genes associated with neuronal function. Cisplatin influences the expression of genes implicated in both inflammatory and neuropathic pathologies [102]. The infiltration of leukocytes into the nervous system of animals with CIPN symptoms and peripheral and central glial cell activation have also been observed. These alterations are dependent on the chemotherapeutic drug used, its dose, the treatment schedule, and the therapy duration. There is, however, still limited evidence for such phenomena from human studies [105].

Cytokines and chemokines Increased production and release of cytokines [e.g., interleukins (IL): IL-1 $\beta$, IL-6, IL-8, tumor necrosis factor $\alpha$ (TNF $\alpha)$, and interferon $\gamma$ (IFN- $\gamma$ )] and chemokines (e.g., CCL2, and CXCL12, CCL11, CCL3, and CCL4) and decreased expression of anti-inflammatory cytokines (IL-10 and IL-4) are observed after the administration of several chemotherapeutics including paclitaxel, cisplatin and vincristine. IL-1, TNF $\alpha$, and IL- 6 not only cause axonal damage but also facilitate neuron-immune communication and increase the release of bradykinin, serotonin, and histamine. These mediators are able to augment proinflammatory processes and act as sensitizers for nociceptors, thus playing a crucial role in the progression of CIPN. Increased concentrations of cytokines and chemokines in the dorsal root ganglia and spinal cord induce alterations in the Schwann cells of peripheral axons, satellite cells in the dorsal root ganglia, and astrocytes in the spinal cord, which all contribute to CIPN development [102, 106-111].

Recently, using models of CIPN induced by paclitaxel and oxaliplatin, it was shown that the IL-8 signaling pathway is involved in neuroinflammation that results in a progressive neural sensitization [108]. The levels of interleukin IL-6 and IL-6 receptors in women after breast cancer treatment have also been investigated, and these studies revealed that the IL-6 signaling pathway may be an important biological mechanism associated with the persistence of the painful symptoms of CIPN, which may have potential implications for the management of CIPN symptoms [112].

Oxaliplatin administration increases the mRNA levels of proinflammatory cytokines and chemokines, and this effect is strongly correlated with the development of mechanical hypersensitivity observed in rats. Oxaliplatin-induced pain is accompanied by the upregulation of PI3K-mTOR, enhanced mTOR-mediated signals and increased ERK phosphorylation. Taken together, these findings suggest that the mechanism of the development of oxaliplatin-induced neuropathy resembles that of inflammatory pain [113].

Crosstalk between the nervous system and the immune system during chemotherapy is well known to occur, and the upregulation of chemokines is a key phenomenon that modulates this effect. Chemokines, which were originally identified as regulators of peripheral immune cell trafficking, are expressed on neurons and glial cells in the central nervous system. As such, they are regarded as important contributors to pain signaling in CIPN. The expression of chemokines and their receptors, (e.g., CX3CL1/CX3CR1, CCL2/CCR2, 
CXCL1/CXCR2, CXCL12/CXCR4 and CCL3/CCR5) is altered in CIPN $[114,115]$.

The $\mathrm{C}-\mathrm{C}$ motif chemokine ligand 2 (CCL2, also known as monocyte chemoattractant protein 1, MCP1) [2] and its receptor CCR2 are increased in the small dorsal root ganglion neurons of paclitaxel-treated rats with CIPN symptoms. CCR2 gene knockdown or CCR2 blockade reduces neuropathic pain in mice $[17,116]$.

In addition to increasing the level of CCL2, paclitaxel also increases the level of CCL3 in the lumbar dorsal root ganglion [109].

Increased levels of CCL2 and CCR2 in the dorsal root ganglia have also been observed to be accompanied by mechanical hypersensitivity in oxaliplatin-treated rats [117].

Using a mouse model of vincristine-induced CIPN, Montague and colleagues demonstrated that CCL2/CCR2 signaling plays a crucial role in the development of allodynia in CX3CR1-deficient mice. They suggested that this effect might be due to an interaction between CX3CR1 and CCR2 receptors in monocytes [118].

Vincristine and paclitaxel upregulate $\mathrm{C}-\mathrm{X}-\mathrm{C}$ motif chemokine ligand 12 (CXCL12) in the dorsal horn ganglia. This chemokine is a ligand of CXCR4 (CD184, C-X-C chemokine receptor type 4). CXCL12 can be released from the central terminals of dorsal root ganglion neurons into spinal cord dorsal horn neurons and functions as an attractant for T-lymphocytes and monocytes. The activation of CXCR4 increases the intracellular calcium concentration and stimulates the chemotaxis of immune cells to the site of inflammation [17].

Immunological ligands and receptors Toll-like receptors (TLR) are transmembrane proteins that function as sensors of a diverse range of endogenous and exogenous substances that are potentially harmful to the body. They are widely expressed on immune cells, enterocytes, sensory neurons and glial cells. When activated, they modulate inflammatory responses in body tissues to detect various pathogens. TLR4 is specialized to detect bacterial pathogens, and TLR3 detects viral pathogens. TLR4 is also activated in many neuropathic pain states [119], including those associated with CIPN caused by paclitaxel [120-125], oxaliplatin [126, 127], cisplatin [6, 128] and vincristine [129]. TLR4 activation by chemotherapeutics is responsible for the increase in proinflammatory cytokine expression in the peripheral and central nervous systems. TLR4 signals that promote the expression of MCP-1 are increased in the dorsal root ganglia of rats with paclitaxel-induced hyperalgesia, and this effect can be prevented by cotreating the animals with TLR4 antagonists during chemotherapy [116].

Similarly, mice with genetic TLR4 or TLR3 knockout do not develop hyperalgesia after treatment with cisplatin $[17,110]$.
Sex-dependent differences in pain sensitivity were shown recently in paclitaxel-treated rats with CIPN symptoms [130], and it has been demonstrated that the lipopolysaccharide-induced activation of spinal TLR4 mediates mechanical allodynia in male mice but not in female mice. This receptor also plays a sex-specific role in inflammatory and neuropathic pain in male mice, and this sex-specific response is limited to the spinal cord [131].

The cellular and molecular mechanisms of TLR9 signaling in CIPN caused by paclitaxel were investigated using Tlr9-deficient mice of both sexes. It was found that in male mice but not in female mice, a Tlr9 mutation attenuated the development of neuropathic pain caused by paclitaxel. Moreover, a TLR9 antagonist injected intraplantarly alleviated paclitaxel-induced mechanical allodynia only in male wild-type mice. Taken together, this study shows the involvement of sex-dimorphic TLR9 signaling (in both the spinal cord and the periphery) in CIPN and suggests that TLR9 signaling pathway promotes CIPN in male mice. It was postulated that the activation of TLR9 in macrophages in male mice results in the release of proinflammatory cytokines and chemokines and that this is the basis for CIPN-related mechanical allodynia in male mice [120].

Immune cells T-cells Paclitaxel-induced mechanical allodynia is prolonged in T-cell-deficient ( $\operatorname{Rag} 1-/-)$ mice compared to their wild-type littermates, and it was demonstrated that CD8 + T-cells in the dorsal root ganglia are critical for recovery from CIPN [110, 132]. Similar results have been shown for cisplatin [133]. T cells are also involved in the preventive effects of histone deacetylase six inhibitors on cisplatin-induced mechanical allodynia and mitochondrial deficits in dorsal root ganglion neurons [134].

On the other hand, in male C57BL/6 J mice treated with paclitaxel or oxaliplatin, significant mechanical allodynia is accompanied by increased circulating CD4 + and CD8 + T-cells [109].

Macrophages The intestinal mucosa is the largest immune organ and contains an abundance of macrophages, which are key cells for homeostasis maintenance. Macrophages regulate the development of behavioral hypersensitivity and the loss of distal epidermal nerve fibers and hence play an important role in paclitaxel-related neuropathy $[116,135]$.

It was recently postulated that the gut microbiota may influence CIPN through macrophages [110], and after chemotherapy, the number of $\mathrm{CD} 11 \mathrm{~b}+\mathrm{CD} 45^{\mathrm{hi}}$ cells, which are presumably macrophages, is significantly lower in the dorsal root ganglia of mice that receive water containing antibiotics than those receiving water alone [136].

In rats, intravenous immunoglobulins are effective as a therapeutic option, reducing macrophage infiltration and the severity of bortezomib-induced CIPN [103]. 
Astrocytes As the most abundant cells in the CNS, astrocytes participate in diverse functional processes, including brain metabolism and neuronal transmission. The activation of astrocytes and the release of modulators from these stimulated cells have been implicated in neuropathic pain of various origins [110], including paclitaxel-induced CIPN [107, 109].

Microglia The role of spinal microglia in neuropathic pain syndromes is complex [137] and, at least for CIPN, is not completely understood. Investigations of the role of microglia in CIPN have presented opposing findings. Some researchers gave reported increased microglial activation in response to vincristine and paclitaxel administration [138-141]. On the other hand, there are also data that suggest that microglia do not play a significant role in CIPN, at least when compared to the pivotal role of astrocytes in this clinical entity [142].

It should be emphasized that microglia, as immune cells, are an abundant source of pain-associated substances, including IL-1 $\beta$, IL-6, and TNF $\alpha$. Minocycline, an inhibitor of macrophages, monocytes and microglia, as well as a matrix metalloproteinase-9 (MMP-9) inhibitor, attenuates mechanical hyperalgesia induced by oxaliplatin and paclitaxel $[17,110]$.

In cisplatin-treated mice that show symptoms of mechanical allodynia and sensory deficits, the activation of microglia, but not astrocytes, in the spinal cord is observed. This is accompanied by increased mRNA levels of inflammatory state-related molecules (IL-1 $\beta$, IL-6, TNF $\alpha$, and inducible nitric oxide synthase). Minocycline alleviates cisplatininduced behavioral signs of neuropathy in this mouse model [143].

A large number of studies have focused on the connection of the gut microbiota to chemotherapy-induced diarrhoea or mucositis [110], but there is also recent evidence for the involvement of the gut microbiome and impaired microglia function in the development of CIPN [104, 136, 144]. The microbiota is critical for controlling microglial maturation and function, and the treatment of adult mice with antibiotics results in impaired maturation and innate immune functionality of these immune cells in the brain. It has been hypothesized that the gut microbiome connects the microbiome-gut-brain and neuroimmune-endocrine axes, and this network might influence key components involved in CIPN.

Recently, a potential role of the gut microbiome in the development of CIPN caused by paclitaxel was suggested [138]. Spinal microgliosis is also involved in paclitaxelinduced pain and a link between the gut microbiota, microglial activation and neuroinflammation in CIPN has been reported [144]. In this study, paclitaxel decreased the amount of beneficial bacteria such as Akkermansia muciniphila OTU, which was previously shown to promote the integrity of the epithelial cell layer and improve barrier function [144]. It was then hypothesized that chemotherapy causes barrier dysfunction, resulting in increased systemic exposure to bacterial products and metabolites, which in turn promotes systemic inflammation and pain. Also, oxaliplatininduced mechanical hyperalgesia is reduced in germ-free mice and in mice pretreated with antibiotics, which further suggests that the gut microbiota promotes the development of oxaliplatin-induced mechanical hypersensitivity and neuroinflammation. These effects appear to be mediated, in part, by TLR4 expressed on macrophages [136].

Schwann cells Schwann cells are glial cells in the peripheral nervous system that form a thin myelin sheet around the axons of motor and sensory neurons, thus enabling saltatory conduction of action potentials. Furthermore, they are a source of vasoactive mediators and play an important role in the recruitment of immune cells from the vasculature. Schwann cells have been shown to express various TLRs and play a key role in neuroinflammation resulting from the administration of antitumor drugs [29, 110]. Recently, Imai and colleagues investigated the effects of antitumor drugs on Schwann cells. They showed that the exposure of primary cultured rat Schwann cells to paclitaxel, cisplatin, or oxaliplatin at concentrations lower than those required to induce neurotoxicity in cultured rat dorsal root ganglion neurons induced cytotoxicity and reduced myelin basic protein expression. These chemotherapeutic drugs disrupted myelin formation by Schwann cells. Platinum derivatives induced mitochondrial dysfunction in cultured Schwann cells, while paclitaxel led to the dedifferentiation of Schwann cells into an immature state characterized by increased expression of p75 and galectin-3. In line with this, in the mouse sciatic nerve, repeated injection of paclitaxel increased the expression of p75 and galectin-3 in Schwann cells [145].

Central nervous system structures and neurotransmitters In the course of CIPN structural damage to the peripheral nervous system induces abnormal central nervous system processing. The involvement of the brain and spinal cord in CIPN development has become a subject of extensive studies but at present the impact of CIPN on brain structures and levels of central nervous system neurotransmitters is still understudied.

To elucidate the role of central nervous system neurons in altered behavioral sensitivity seen during chronic pain conditions Samineni and colleagues [146] studied spontaneous and thermally-evoked firing patterns of ventrolateral periaqueductal gray neurons in rats treated with paclitaxel. In this research, ventrolateral periaqueductal gray neurons displayed increased neuronal activity and changes in thermal pain-evoked neuronal activity. This involved elevated levels of spontaneous firing and increased responsiveness to non-noxious stimuli (allodynia) as well as noxious thermal 
stimuli (hyperalgesia) as compared to controls. Furthermore, after paclitaxel treatment only excitatory neuronal responses were observed to both non-noxious and noxious thermal stimuli. Systemic administration of gabapentin induced significant dose-dependent decreases in the elevated spontaneous and thermally-evoked ventrolateral periaqueductal gray neuronal firing to both non-noxious and noxious thermal stimuli in paclitaxel-treated rats but not in naïve rats. These results showed a strong correlation between behavioral hypersensitivity to thermal stimuli and increased firing of ventrolateral periaqueductal gray neurons in allodynia and hyperalgesia that occur after paclitaxel administration.

The reorganization of neural circuits in the brain in CIPN have been also observed by Ferris and colleagues [147]. They conducted an imaging study to evaluate the impact of paclitaxel treatment (8 days) on brain neural circuitry in rats. Paclitaxel-treated rats were more sensitive to a cold stimulus compared to controls. Brain areas involved in the emotional and motivational responses to chronic pain were also impacted by paclitaxel treatment. Affected brain regions included the prefrontal cortex, amygdala, hippocampus, hypothalamus and the striatum/nucleus accumbens. This study confirmed central nervous system effects of chemotherapy and showed that neuropathic pain is modulated by emotion and motivation, and influences activity of the periaqueductal gray and brainstem to modulate pain perception.

The central changes observed during paclitaxel-induced CIPN are likely to be caused by the neurotoxic effects triggered by this antitumor drug at the periphery because paclitaxel has a very low ability to cross the blood-brain barrier [148].

CIPN-related alterations are also observed at the spinal cord level and paclitaxel-injected animals showed increased spontaneous activity of wide-dynamic range neurons and decreased expression of glutamate transporters in the lumbar spinal dorsal horn. These results suggest a state of increased excitability that develops in spinal pain-signaling neurons as a consequence of decreased glutamate clearance. These changes in dorsal horn contribute to the hyperresponsiveness to sensory stimuli seen in animals treated with paclitaxel and may play a role in pain seen in patients on paclitaxel therapy [149].

Reorganization of some brain areas, including the frontal lobe, insular cortex, somatosensory cortex, thalamus, periaqueductal gray and precuneus has been demonstrated in CIPN. A study using fMRI explored central pain processing in myeloma patients with CIPN. This study showed that painful stimuli delivered to neuropathy-affected and symptom-free sites in patients suffering from CIPN evoked differential activation of distinct cortical regions [150].

An association between cerebral resting-state perfusion and CIPN symptoms was demonstrated in patients with breast cancer and CIPN symptoms. These results suggest that gray matter density decrease and associated perfusion decrease may interfere with CIPN-symptoms and patient symptom perception. Individuals showing gray matter density decrease may report less severe symptoms of CIPN, while showing less CIPN symptom-related perfusion change [151].

Altered levels of several neurotransmitters, such as catecholamines, histamine, serotonin, glutamate and $\gamma$-aminobutyric acid (GABA), are associated with CIPN caused by vincristine [152, 153], paclitaxel [154], oxaliplatin [155-157] and bortezomib [158].

The analgesic effect mediated by monoamines: serotonin and noradrenaline, is due to the blockade of nociceptive transmission at the spinal dorsal horn. This activity is independent of their antidepressant effect. Antidepressants that act at serotonin and noradrenaline reuptake are clinically relevant in CIPN treatment [19].

Using an animal model of paclitaxel-induced CIPN, increased activity of serotoninergic neurons of the rostroventromedial medulla has been demonstrated in rats. The immunohistochemical analysis of serotonin showed increased expression at the superficial dorsal horn (laminae I-II) and higher levels of $5-\mathrm{HT}_{3}$ receptors in the superficial dorsal horn (laminae I-II) of paclitaxel-injected animals. The intrathecal administration of the $5-\mathrm{HT}_{3}$ receptor antagonist (ondansetron) reversed mechanical and cold hypersensitivity of paclitaxel-treated rats. These results indicate that CIPN is associated with increased recruitment of descending serotonergic modulation from the rostroventromedial medulla which affects the spinal serotoninergic system and might account for pain hypersensitivity mediated by spinal $5-\mathrm{HT}_{3}$ receptors [159].

Animal models of neuropathic pain revealed that noradrenaline is a neurotransmitter that plays an important role in the inhibition of this chronic pain type. The increase of noradrenaline in the spinal cord by reuptake inhibition directly attenuates neuropathic pain through $\alpha_{2}$-adrenergic receptors. Moreover, noradrenaline acts within the locus coeruleus and improves the function of the impaired descending noradrenergic inhibitory system. Serotonin and dopamine may reinforce the noradrenergic effects to inhibit neuropathic pain [160].

The role of descending noradrenergic modulation of spinal nociceptive transmission in CIPN was studied in paclitaxel-treated rats [26]. It has been shown that in the paclitaxel-induced CIPN rat model, the descending noradrenaline-mediated inhibition affecting nociceptive transmission at the spinal cord is potentiated. It has been suggested that the enhanced noradrenergic inhibition during CIPN may represent an adaptive mechanism of the descending noradrenergic pain control system to the increased peripheral nociceptive input. Pharmacological stimulation of $\alpha_{2}$-adrenergic receptors at the spinal cord level using 
noradrenergic drugs (e.g., reboxetine, clonidine) may, therefore, represent a promising therapeutic opportunity to treat CIPN-related pain [26].

Glutamate transporters, such as glutamate transporter 1 (GLT-1) and glutamate aspartate transporter (GLAST, EAAT1), are abundantly expressed in astrocytes, where they act to remove synaptically released glutamate from the synaptic cleft [161]. These transport proteins have been shown to be downregulated in activated astrocytes, and this results in impaired functioning of these proteins, leading to neuronal hyperexcitability. Importantly, the downregulation of both GLT-1 and GLAST has been observed in paclitaxel-treated [149, 162, 163], oxaliplatin-treated [164] and bortezomibtreated neuropathic rats [165]. In our recent study [166], a single dose and repeated doses of ceftriaxone, a beta-lactam antibiotic that acts by upregulating GLT-1 expression, thus increasing glutamate reuptake in the CNS [167-169], was tested for its ability to attenuate early-phase and late-phase tactile allodynia and cold hyperalgesia in oxaliplatin-treated mice. The repeated intraperitoneal administration of $200 \mathrm{mg} /$ $\mathrm{kg}$ ceftriaxone prevented the development of late-phase tactile allodynia, but ceftriaxone showed no antiallodynic properties in the cold plate test. These results confirmed previous findings showing that ceftriaxone (through increased GLT-1 expression) affected mechanical rather than thermal (cold) allodynia, which suggests that the biological functions of GLT-1 are more associated with the regulation of the mechanical nociceptive threshold than the cold nociceptive threshold [170].

In addition to decreased astrocytic glutamate reuptake due to GLT-1 and GLAST hypofunction, increased synaptic $\gamma$-aminobutyric acid (GABA) reuptake resulting from the enhanced GAT-1 function should be considered as a phenomenon implicated in CIPN development. The evidence for this is mainly based on the observed significant antiallodynic and antihyperalgesic effects of GAT-1 inhibitors in rodent models of CIPN. Decreased GABAergic neurotransmission due to excessive IL-17 levels in the spinal cord has been linked to CIPN caused by paclitaxel [171], and the inhibition of GABA reuptake with by NO-711, a selective GABA transporter isoform 1 (GAT-1) inhibitor [172], prevents the development of thermal hyperalgesia and allodynia in paclitaxel-treated mice. NO-711 is also therapeutically effective for pre-existing CIPN [173]. Also, GABAergic precursor cell transplants reverse paclitaxel-induced mechanical hypersensitivity [174].

In paclitaxel-treated animals, the enhancement of GAT-1 protein expression, decreased GAT- 3 expression, increased global GABA uptake, as well as suppression of GABAergic tonic inhibition in the spinal dorsal horn are also noted. Paclitaxel-induced neuropathic pain was significantly attenuated by the intrathecal injection of a GAT-1 inhibitor but not a GAT-3 transporter inhibitor. These findings confirm that targeting GAT-1 transporters for reversing disinhibition in the spinal dorsal horn may be a useful approach for treating paclitaxel-induced neuropathic pain [175].

In oxaliplatin-treated rats, the elevation of IL- $1 \beta$, IL-6, and $\mathrm{TNF} \alpha$ levels in the periaqueductal gray matter and the upregulation of IL- $1 \beta$, IL- 6 , and TNF $\alpha$ receptor expression in the plasma membrane in the periaqueductal gray of oxaliplatin-treated rats coincides with decreased GABAergic neurotransmission. The behavioral symptoms noted in these animals include tactile and cold allodynia. The blockade of proinflammatory cytokine receptors results in restored GABA function and the attenuation of mechanical and cold hypersensitivity [176].

The effect of tiagabine, a highly selective GAT-1 inhibitor, on oxaliplatin-induced neuropathic pain in mice was assessed [177]. The intraperitoneal administration of tiagabine at doses of $4 \mathrm{mg} / \mathrm{kg}$ and $8 \mathrm{mg} / \mathrm{kg}$ attenuated tactile allodynia in the von Frey test both $3 \mathrm{~h}$ (acute phase of CIPN) and 7 days (late phase of CIPN) after oxaliplatin injection. Tiagabine was not effective in reducing cold hyperalgesia in either the acute phase or the late phase.

The effect of non-GAT-1 inhibitors on the behavioral symptoms of CIPN is less known; however recent studies have shown that preferential inhibitors of mouse GAT3/4 might attenuate tactile allodynia but not cold allodynia in oxaliplatin-treated mice [178].

\section{Concluding remarks}

Since the survival rate of patients treated with antitumor agents is increasing, CIPN is considered to be a significant cause of decreased quality of life among cancer survivors. The number of analgesic drugs that effectively relieve pain symptoms and are used as an interventional treatment for pre-existing CIPN-related pain is very limited, and the efficacy of these drugs in CIPN is significantly lower than that in other neuropathic pain types. Despite our growing knowledge regarding the mechanisms underlying CIPN, this clinical entity is still not preventable. Currently, animal models of CIPN are widely used to investigate CIPN pathophysiology and to develop potential novel therapies for this debilitating condition. These preclinical models aim to reflect the impairments observed in CIPN in humans and they provide a deeper insight into the mechanisms underlying the initiation and maintenance of CIPN.

On the other hand, the lack of translational progress in pain studies has been observed, recently. Basic science knowledge obtained using both in vivo and in vitro models has not resulted in a dynamic development of novel drugs for CIPN and even a broader use of genetically-manipulated animals to study CIPN or assays that more closely resemble clinical picture of CIPN-related pain states has not increased 
the effectiveness of drug discovery and development of analgesics for CIPN. Therefore, a careful re-examination of animal models of CIPN-related pain seems an urgent need.

Pain is a complex phenomenon which is affected by a wide range of modulatory factors, including sex, genotype and social communication, and all of them must be considered when translating results obtained in animal model to humans [179-182]. In addition to genetic and neurochemical differences between rodents and humans, there are also neuroanatomical differences in pain pathways between rodents and humans (i.e., rodent and primate dorsal horns, the forebrain) and this might be crucial for the observed distinct pain sensation. Hence, a greater emphasis on studies of pain in humans is strongly recommended [179].

Importantly, previous pain studies were focused on the sensory dimension of pain with almost no analysis of the affective component of pain, and empathy-like responses in experimental animals were, therefore, neglected [183]. The affective aspect of pain is still not well-addressed, so there is a strong need to study the affective component of pain in animal models [182].

Several other factors should be also considered at the preclinical phase as potential factors leading to translational failure. Firstly, animal models might not be the best representation of the clinical situation and it is of key importance to use only the most effective and reliable animal models that mimic the clinical situation as close as possible (construct validity). Scientists need to be aware of the existence of various available models, and how they differ in characteristics and efficacy in causing CIPN. In this context, it seems that the available animal CIPN models are manifestations of gain in sensory functions which measure mainly allodynia, hyperalgesia and neurophysiological alterations in nerve function, whereas many patients, at least in the chronic phase of CIPN also report other symptoms, such as numbness, tingling and ongoing pain. This may compromise the clinical relevance of these animal models for chronic CIPN studies [181, 184]. Therefore, the use of animal models that replicate all symptoms observed in humans is strongly demanded but is still a very challenging endeavor as some symptoms occur spontaneously and are very difficult to replicate in animals. At present, measures of ongoing pain in rodents is an emerging phenomenon.

Another key issue regarding the clinical relevance of animal models is that the majority of them utilize cancer-free animals, whereas in the clinical situation most CIPN patient have or experienced previously cancer. Cancer may significantly confound the effectiveness (both: pharmacokinetic and pharmacodynamics properties) of drugs used for CIPN treatment $[181,184]$.

Also, doses and mode of deliveries of the anti-tumor drugs may not reflect the clinical situation, and many preclinical studies do not seem to be fully randomized and blinded.

Polyneuropathy characteristics is also important and there are some serious concerns about the clinical relevance of the time courses frequently studied in animals. Acute CIPN affects patients within the first 6 months and chronic CIPN has been observed in patients approximately 2 years after treatment. Therefore, the short duration of the majority of animal models of CIPN likely regard the acute phase only [181].

Finally, most studies use only male animals and evoke limb withdrawal to mechanical stimuli $[180,181]$. In the clinic, many CIPN-inducing drugs are frequently used to treat female cancer patients (e.g., ovarian or breast cancers), thus the use of both sexes of animals in the modeling of CIPN is warranted and will likely improve the validity of animal models [26, 181].

Taken together, it is important to realize that at present no animal model represents the full clinical situation perfectly because of interspecies differences and inevitable differences between the conditions created in animals and those observed in human CIPN. Research findings, therefore, need to be confirmed in multiple animal models as comparable results in multiple animal models of CIPN would increase our confidence in the results and their applicability for the clinical situation.

Since many of the mechanisms that underlie CIPN overlap, they may reinforce each other. Hence, combination therapies seem to be potentially useful and valuable approaches to prevent CIPN development or treat its symptoms. Unfortunately, at present, the number of clinical trials focused on testing combination drug therapies for neuropathic pain is scarce, and there are no clear algorithms describing how to use combined drugs in neuropathic patients.

Importantly, the patient-reported severity of CIPN symptoms are more valuable than the assessments provided by clinicians. One should also realize that comorbidities present in patient populations in addition to cancer itself are likely to influence nociception and CIPN-related neuropathic pain pathophysiology. Therefore, a more effective treatment for CIPN will require close cooperation between oncologists, neurologists, psychiatrists and specialists from other fields of medicine to ensure that CIPN patients are effectively cured and monitored.

A better understanding of the mechanisms of CIPN is important for the identification of novel preventative therapies. Deeper insight into mechanisms underlying axonal degeneration in CIPN is, therefore, an urgent need. Since degenerative processes within the peripheral nervous system are only a part of CIPN, we also need to understand the role of central nervous system changes (neuroplasticity and the central sensitization of neuropathic pain), neuromodulators, 
neurotransmitters and receptors implicated in the phenomena that induce CIPN [185].

Acknowledgements Data from the author's own research presented in this paper was obtained with financial support from the National Science Centre, Poland [Grant Number UMO-2015/17/B/NZ7/02937].

Open Access This article is licensed under a Creative Commons Attribution 4.0 International License, which permits use, sharing, adaptation, distribution and reproduction in any medium or format, as long as you give appropriate credit to the original author(s) and the source, provide a link to the Creative Commons licence, and indicate if changes were made. The images or other third party material in this article are included in the article's Creative Commons licence, unless indicated otherwise in a credit line to the material. If material is not included in the article's Creative Commons licence and your intended use is not permitted by statutory regulation or exceeds the permitted use, you will need to obtain permission directly from the copyright holder. To view a copy of this licence, visit http://creativecommons.org/licenses/by/4.0/.

\section{References}

1. Colloca L, Ludman T, Bouhassira D, Baron R, Dickenson AH, Yarnitsky D, et al. Neuropathic pain. Nat Rev Dis Prim. 2017;3:17002. https://doi.org/10.1038/nrdp.2017.2.

2. Kwiatkowski K, Mika J. The importance of chemokines in neuropathic pain development and opioid analgesic potency. Pharmacol Rep. 2018;70:821-30. https://doi.org/10.1016/j.phare p.2018.01.006.

3. Bouhassira D. Neuropathic pain: definition, assessment and epidemiology. Rev Neurol (Paris). 2019;175:16-25. https://doi. org/10.1016/j.neurol.2018.09.016.

4. Zilliox LA. Neuropathic pain. Continuum (Minneap Minn). 2017;23:512-32. https://doi.org/10.1212/CON.0000000000 000462 .

5. Jayarajan P, Nirogi R, Shinde A, Goura V, Babu VA, Yathavakilla $\mathrm{S}$, et al. 5-HT6 receptor antagonist attenuates the memory deficits associated with neuropathic pain and improves the efficacy of gabapentinoids. Pharmacol Rep. 2015;67:934-42. https://doi. org/10.1016/j.pharep.2015.03.013.

6. Woller SA, Corr M, Yaksh TL. Differences in cisplatin-induced mechanical allodynia in male and female mice. Eur $\mathrm{J}$ Pain. 2015;19:1476-85. https://doi.org/10.1002/ejp.679.

7. Vacca V, Marinelli S, Pieroni L, Urbani A, Luvisetto S, Pavone F. Higher pain perception and lack of recovery from neuropathic pain in females: a behavioural, immunohistochemical, and proteomic investigation on sex-related differences in mice. Pain. 2014;155:388-402. https://doi.org/10.1016/j.pain.2013.10.027.

8. Molassiotis A, Cheng HL, Leung KT, Li YC, Wong KH, Au JSK, et al. Risk factors for chemotherapy-induced peripheral neuropathy in patients receiving taxane- and platinum-based chemotherapy. Brain Behav. 2019. https://doi.org/10.1002/brb3.1312.

9. Hu S, Huang KM, Adams EJ, Loprinzi CL, Lustberg MB. Recent developments of novel pharmacologic therapeutics for prevention of chemotherapy-induced peripheral neuropathy. Clin Cancer Res. 2019;25:6295-301. https://doi.org/10.1158/1078-0432. CCR-18-2152.

10. Ciaramitaro P, Cruccu G, de Tommaso M, Devigili G, Fornasari D, Geppetti P, et al. A Delphi consensus statement of the Neuropathic Pain Special Interest Group of the Italian Neurological Society on pharmacoresistant neuropathic pain. Neurol Sci. 2019;40:1425-31. https://doi.org/10.1007/s10072-019-03870-y.
11. Siegel RL, Miller KD, Jemal A. Cancer statistics, 2020. CA Cancer J Clin. 2020;70:7-30. https://doi.org/10.3322/caac.21590.

12. Cancer n.d. https://www.who.int/health-topics/cance $\mathrm{r} \# \mathrm{tab}=\mathrm{tab} 1$. Accessed 22 Jan 2020.

13. Wallington M, Saxon EB, Bomb M, Smittenaar R, Wickenden M, McPhail S, et al. 30-day mortality after systemic anticancer treatment for breast and lung cancer in England: a population-based, observational study. Lancet Oncol. 2016;17:1203-16. https://doi. org/10.1016/S1470-2045(16)30383-7.

14. Tanay MAL, Armes J, Ream E. The experience of chemotherapy-induced peripheral neuropathy in adult cancer patients: a qualitative thematic synthesis. Eur J Cancer Care (Engl). 2017;26:e12443. https://doi.org/10.1111/ecc.12443.

15. Cavaletti G, Alberti P, Argyriou AA, Lustberg M, Staff NP, Tamburin S. Chemotherapy-induced peripheral neurotoxicity: a multifaceted, still unsolved issue. J Peripher Nerv Syst. 2019;24:S6-12. https://doi.org/10.1111/jns.12337.

16. Cioroiu C, Weimer LH. Update on chemotherapy-induced peripheral neuropathy. Curr Neurol Neurosci Rep. 2017;17:47. https://doi.org/10.1007/s11910-017-0757-7.

17. Flatters SJL, Dougherty PM, Colvin LA. Clinical and preclinical perspectives on Chemotherapy-Induced Peripheral Neuropathy (CIPN): a narrative review. Br J Anaesth. 2017;119:737-49. https ://doi.org/10.1093/bja/aex229.

18. Blanton HL, Brelsfoard J, DeTurk N, Pruitt K, Narasimhan M, Morgan DJ, et al. Cannabinoids: current and future options to treat chronic and chemotherapy-induced neuropathic pain. Drugs. 2019;79:969-95. https://doi.org/10.1007/s40265-01901132-x.

19. Sisignano M, Baron R, Scholich K, Geisslinger G. Mechanismbased treatment for chemotherapy-induced peripheral neuropathic pain. Nat Rev Neurol. 2014;10:694-707. https://doi. org/10.1038/nrneurol.2014.211.

20. Starobova H, Vetter I. Pathophysiology of chemotherapy-induced peripheral neuropathy. Front Mol Neurosci. 2017;10:174. https ://doi.org/10.3389/fnmol.2017.00174.

21. Miltenburg NC, Boogerd W. Chemotherapy-induced neuropathy: a comprehensive survey. Cancer Treat Rev. 2014;40:872-82. https://doi.org/10.1016/j.ctrv.2014.04.004.

22. Beijers AJM, Jongen JLM, Vreugdenhil G. Chemotherapyinduced neurotoxicity: the value of neuroprotective strategies. Neth J Med. 2012;70:18-25.

23. Ma J, Kavelaars A, Dougherty PM, Heijnen CJ. Beyond symptomatic relief for chemotherapy-induced peripheral neuropathy: targeting the source. Cancer. 2018;124:2289-98. https://doi. org/10.1002/cncr.31248.

24. Glimelius B, Manojlovic N, Pfeiffer P, Mosidze B, Kurteva G, Karlberg M, et al. Persistent prevention of oxaliplatin-induced peripheral neuropathy using calmangafodipir (PledOx $\left.{ }^{\circledR}\right)$ ): a placebo-controlled randomised phase II study (PLIANT). Acta Oncol (Madr). 2018;57:393-402. https://doi.org/10.1080/02841 86X.2017.1398836.

25. Jin HY, Lee NY, Ko HA, Lee KA, Park TS. Comparison of sensory tests and neuronal quantity of peripheral nerves between streptozotocin (STZ)-induced diabetic rats and paclitaxel (PAC)-treated rats. Somatosens Mot Res. 2016. https://doi. org/10.1080/08990220.2016.1239577.

26. Costa-Pereira JT, Ribeiro J, Martins I, Tavares I. Role of spinal cord $\alpha_{2}$-adrenoreceptors in noradrenergic inhibition of nociceptive transmission during chemotherapy-induced peripheral neuropathy. Front Neurosci. 2020. https://doi.org/10.3389/fnins 2019.01413.

27. Beijers A, Mols F, Dercksen W, Driessen C, Vreugdenhil G. Chemotherapy-induced peripheral neuropathy and impact on quality of life 6 months after treatment with chemotherapy. 
J Community Support Oncol. 2014;12:401-6. https://doi. org/10.12788/jcso.0086.

28. Seretny M, Currie GL, Sena ES, Ramnarine S, Grant R, MacLeod MR, et al. Incidence, prevalence, and predictors of chemotherapy-induced peripheral neuropathy: a systematic review and meta-analysis. Pain. 2014;155:2461-70. https://doi. org/10.1016/j.pain.2014.09.020.

29. Eldridge S, Guo L, Hamre J. A comparative review of chemotherapy-induced peripheral neuropathy in in vivo and in vitro models. Toxicol Pathol. 2020;48:190-201. https://doi.org/10.1177/01926 23319861937.

30. Baldwin RM, Owzar K, Zembutsu H, Chhibber A, Kubo M, Jiang $\mathrm{C}$, et al. A genome-wide association study identifies novel loci for paclitaxel-induced sensory peripheral neuropathy in CALGB 40101. Clin Cancer Res. 2012;18:5099-109. https:// doi.org/10.1158/1078-0432.CCR-12-1590.

31. Ciruelos E, Apellániz-Ruiz M, Cantos B, Martinez-Jáñez N, Bueno-Muiño C, Echarri M, et al. A pilot, Phase II, randomized, open-label clinical trial comparing the neurotoxicity of three dose regimens of nab-paclitaxel to that of solvent-based paclitaxel as the first-line treatment for patients with human epidermal growth factor receptor type 2-negative metastatic breast cancer. Oncologist. 2019;24:e1024-e10331033. https://doi.org/10.1634/ theoncologist.2017-0664.

32. Chan A, Hertz DL, Morales M, Adams EJ, Gordon S, Tan CJ, et al. Biological predictors of chemotherapy-induced peripheral neuropathy (CIPN): MASCC neurological complications working group overview. Support Care Cancer. 2019;27:3729-37. https://doi.org/10.1007/s00520-019-04987-8.

33. Taleb O, Bouzobra F, Tekin-Pala H, Meyer L, Mensah-Nyagan AG, Patte-Mensah C. Behavioral and electromyographic assessment of oxaliplatin-induced motor dysfunctions: evidence for a therapeutic effect of allopregnanolone. Behav Brain Res. 2017;320:440-9. https://doi.org/10.1016/j.bbr.2016.10.040.

34. Bakogeorgos M, Georgoulias V. Risk-reduction and treatment of chemotherapy-induced peripheral neuropathy. Expert Rev Anticancer Ther. 2017;17:1045-60. https://doi.org/10.1080/14737 140.2017.1374856.

35. Bonhof CS, Poll-Franse LV, Vissers PAJ, Wasowicz DK, Wegdam JA, Révész D, et al. Anxiety and depression mediate the association between chemotherapy-induced peripheral neuropathy and fatigue: results from the population-based PROFILES registry. Psychooncology. 2019;28:1926-33. https://doi. org/10.1002/pon.5176.

36. Beijers AJM, Bonhof CS, Mols F, Ophorst J, de Vos-Geelen J, Jacobs EMG, et al. Multicenter randomized controlled trial to evaluate the efficacy and tolerability of frozen gloves for the prevention of chemotherapy-induced peripheral neuropathy. Ann Oncol. 2020;31:131-6. https://doi.org/10.1016/J.ANNON C.2019.09.006.

37. Park H-S, Kim C-J, Kwak H-B, No M-H, Heo J-W, Kim T-W. Physical exercise prevents cognitive impairment by enhancing hippocampal neuroplasticity and mitochondrial function in doxorubicin-induced chemobrain. Neuropharmacology. 2018;133:451-61. https://doi.org/10.1016/j.neuropharm 2018.02.013.

38. Walczak P, Janowski M. Chemobrain as a product of growing success in chemotherapy-focus on glia as both a victim and a cure. Neuropsychiatry (London). 2019. https://doi.org/10.4172/ Neuropsychiatry.1000565.

39. Kandula T, Farrar MA, Kiernan MC, Krishnan AV, Goldstein D, Horvath L, et al. Neurophysiological and clinical outcomes in chemotherapy-induced neuropathy in cancer. Clin Neurophysiol. 2017;128:1166-75. https://doi.org/10.1016/j.clinph.2017.04.009.

40. Streckmann F, Lehmann HC, Balke M, Schenk A, Oberste M, Heller A, et al. Sensorimotor training and whole-body vibration training have the potential to reduce motor and sensory symptoms of chemotherapy-induced peripheral neuropathy — a randomized controlled pilot trial. Support Care Cancer. 2019;27:2471-8. https://doi.org/10.1007/s00520-018-4531-4.

41. Streckmann F, Balke M, Lehmann HC, Rustler V, Koliamitra C, Elter $\mathrm{T}$, et al. The preventive effect of sensorimotor- and vibration exercises on the onset of Oxaliplatin- or vinca-alkaloid induced peripheral neuropathies-STOP. BMC Cancer. 2018;18:62. https ://doi.org/10.1186/s12885-017-3866-4.

42. Salat K, Moniczewski A, Librowski T. Nitrogen, oxygen or sulfur containing heterocyclic compounds as analgesic drugs used as modulators of the nitroxidative stress. Mini-Reviews Med Chem. 2013;13:335-52. https://doi.org/10.2174/138955751131303 0003.

43. Colvin LA. Chemotherapy-induced peripheral neuropathy. Pain. 2019;160:S1-. https://doi.org/10.1097/j.pain.000000000000154 0.

44. Miao F, Wang R, Cui G, Li X, Wang T, Li X. Engagement of MicroRNA-155 in exaggerated oxidative stress signal and TRPA1 in the dorsal horn of the spinal cord and neuropathic pain during chemotherapeutic oxaliplatin. Neurotox Res. 2019;36:712-23. https://doi.org/10.1007/s12640-019-00039-5.

45. Chłoń-Rzepa G, Ślusarczyk M, Jankowska A, Gawalska A, Bucki A, Kołaczkowski M, et al. Novel amide derivatives of 1,3-dimethyl-2,6-dioxopurin-7-yl-alkylcarboxylic acids as multifunctional TRPA1 antagonists and PDE4/7 inhibitors: a new approach for the treatment of pain. Eur J Med Chem. 2018;158:517-33. https ://doi.org/10.1016/j.ejmech.2018.09.021.

46. Chukyo A, Chiba T, Kambe T, Yamamoto K, Kawakami K, Taguchi K, et al. Oxaliplatin-induced changes in expression of transient receptor potential channels in the dorsal root ganglion as a neuropathic mechanism for cold hypersensitivity. Neuropeptides. 2018;67:95-101. https://doi.org/10.1016/j.npep.2017.12.002.

47. Nakagawa T, Kaneko S. Roles of transient receptor potential ankyrin 1 in oxaliplatin-induced peripheral neuropathy. Biol Pharm Bull. 2017;40:947-53. https://doi.org/10.1248/bpb.b1700243.

48. Miyake T, Nakamura S, Zhao M, So K, Inoue K, Numata T, et al. Cold sensitivity of TRPA1 is unveiled by the prolyl hydroxylation blockade-induced sensitization to ROS. Nat Commun. 2016;7:12840. https://doi.org/10.1038/ncomms 12840 .

49. Sałat K, Cios A, Wyska E, Sałat R, Mogilski S, Filipek B, et al. Antiallodynic and antihyperalgesic activity of 3-[4-(3-trifluoromethyl- phenyl)-piperazin-1-yl]-dihydrofuran-2-one compared to pregabalin in chemotherapy-induced neuropathic pain in mice. Pharmacol Biochem Behav. 2014;122:173-81. https://doi. org/10.1016/j.pbb.2014.03.025.

50. Sałat K, Moniczewski A, Librowski T. Transient receptor potential channels-emerging novel drug targets for the treatment of pain. Curr Med Chem. 2013;20:1409-36. https://doi. org/10.2174/09298673113209990107.

51. Chine VB, Au NPB, Kumar G, Ma CHE. Targeting axon integrity to prevent chemotherapy-induced peripheral neuropathy. Mol Neurobiol. 2019;56:3244-59. https://doi.org/10.1007/s1203 5-018-1301-8.

52. Chine VB, Au NPB, Ma CHE. Therapeutic benefits of maintaining mitochondrial integrity and calcium homeostasis by forced expression of Hsp27 in chemotherapy-induced peripheral neuropathy. Neurobiol Dis. 2019;130:104492. https://doi. org/10.1016/j.nbd.2019.104492.

53. Staff NP, Fehrenbacher JC, Caillaud M, Damaj MI, Segal RA, Rieger S. Pathogenesis of paclitaxel-induced peripheral neuropathy: a current review of in vitro and in vivo findings using rodent and human model systems. Exp Neurol. 2020;324:113121. https ://doi.org/10.1016/j.expneurol.2019.113121. 
54. Jia M, Wu C, Gao F, Xiang H, Sun N, Peng P, et al. Activation of NLRP3 inflammasome in peripheral nerve contributes to paclitaxel-induced neuropathic pain. Mol Pain. 2017;13:174480691771980. https://doi.org/10.1177/1744806917 719804.

55. Chen Y-F, Chen L-H, Yeh Y-M, Wu P-Y, Chen Y-F, Chang L-Y, et al. Minoxidil is a potential neuroprotective drug for paclitaxelinduced peripheral neuropathy. Sci Rep. 2017;7:45366. https:// doi.org/10.1038/srep45366.

56. Ludman T, Melemedjian OK. Bortezomib-induced aerobic glycolysis contributes to chemotherapy-induced painful peripheral neuropathy. Mol Pain. 2019;15:174480691983742. https://doi. org/10.1177/1744806919837429.

57. Tomaszewski A, Büsselberg D. Cisplatin modulates voltage gated channel currents of dorsal root ganglion neurons of rats. Neurotoxicology. 2007;28:49-58. https://doi.org/10.1016/j.neuro .2006.07.005.

58. Leo M, Schmitt L-I, Erkel M, Melnikova M, Thomale J, Hagenacker T. Cisplatin-induced neuropathic pain is mediated by upregulation of $\mathrm{N}$-type voltage-gated calcium channels in dorsal root ganglion neurons. Exp Neurol. 2017;288:62-74. https://doi. org/10.1016/j.expneurol.2016.11.003.

59. Kidd JF, Pilkington MF, Schell MJ, Fogarty KE, Skepper JN, Taylor CW, et al. Paclitaxel affects cytosolic calcium signals by opening the mitochondrial permeability transition pore. J Biol Chem. 2002;277:6504-10. https://doi.org/10.1074/jbc.M1068 02200 .

60. Li Y, Tatsui CE, Rhines LD, North RY, Harrison DS, Cassidy $\mathrm{RM}$, et al. Dorsal root ganglion neurons become hyperexcitable and increase expression of voltage-gated T-type calcium channels (Cav3.2) in paclitaxel-induced peripheral neuropathy. Pain. 2017;158:417-29. https://doi.org/10.1097/j.pain.0000000000 000774 .

61. Tomita S, Sekiguchi F, Deguchi T, Miyazaki T, Ikeda Y, Tsubota M, et al. Critical role of Cav3.2 T-type calcium channels in the peripheral neuropathy induced by bortezomib, a proteasome-inhibiting chemotherapeutic agent, in mice. Toxicology. 2019;413:33-9. https://doi.org/10.1016/j.tox.2018.12.003.

62. Ogihara T, Nakagawa T, Hayashi M, Koyanagi M, Yonezawa A, Omura T, et al. Improvement of peripheral vascular impairment by a phosphodiesterase type 5 inhibitor tadalafil prevents oxaliplatin-induced peripheral neuropathy in mice. J Pharmacol Sci. 2019;141:131-8. https://doi.org/10.1016/j.jphs.2019.10.005.

63. Malacrida A, Meregalli C, Rodriguez-Menendez V, Nicolini G. Chemotherapy-induced peripheral neuropathy and changes in cytoskeleton. Int J Mol Sci. 2019;20:2287. https://doi. org/10.3390/ijms20092287.

64. Turkiew E, Falconer D, Reed N, Höke A. Deletion of Sarm1 gene is neuroprotective in two models of peripheral neuropathy. J Peripher Nerv Syst. 2017;22:162-71. https://doi.org/10.1111/ jns.12219.

65. Geisler S, Doan RA, Strickland A, Huang X, Milbrandt J, DiAntonio A. Prevention of vincristine-induced peripheral neuropathy by genetic deletion of SARM1 in mice. Brain. 2016;139:3092108. https://doi.org/10.1093/brain/aww251.

66. Yamamoto S, Kawashiri T, Higuchi H, Tsutsumi K, Ushio S, Kaname T, et al. Behavioral and pharmacological characteristics of bortezomib-induced peripheral neuropathy in rats. J Pharmacol Sci. 2015;129:43-50. https://doi.org/10.1016/j. jphs.2015.08.006.

67. DiAntonio A. Axon degeneration. Pain. 2019;160:S17-22. https ://doi.org/10.1097/j.pain.0000000000001528.

68. Meyer L, Patte-Mensah C, Taleb O, Mensah-Nyagan AG. Allopregnanolone prevents and suppresses oxaliplatin-evoked painful neuropathy: multi-parametric assessment and direct evidence. Pain. 2011;152:170-81. https://doi.org/10.1016/j. pain.2010.10.015

69. Fukuda Y, Li Y, Segal RA. A mechanistic understanding of axon degeneration in chemotherapy-induced peripheral neuropathy. Front Neurosci. 2017. https://doi.org/10.3389/fnins.2017.00481.

70. Lisse TS, Middleton LJ, Pellegrini AD, Martin PB, Spaulding EL, Lopes O, et al. Paclitaxel-induced epithelial damage and ectopic MMP-13 expression promotes neurotoxicity in zebrafish. Proc Natl Acad Sci. 2016;113:E2189-E21982198. https://doi. org/10.1073/pnas.1525096113.

71. Pease-Raissi SE, Pazyra-Murphy MF, Li Y, Wachter F, Fukuda Y, Fenstermacher SJ, et al. Paclitaxel reduces axonal Bclw to initiate IP3R1-dependent axon degeneration. Neuron. 2017;96(373386):e6. https://doi.org/10.1016/j.neuron.2017.09.034.

72. Geisler S, Doan RA, Cheng GC, Cetinkaya-Fisgin A, Huang SX, Höke A, et al. Vincristine and bortezomib use distinct upstream mechanisms to activate a common SARM1-dependent axon degeneration program. JCI Insight. 2019. https://doi.org/10.1172/ jci.insight. 129920.

73. Liu H, Smith CB, Schmidt MS, Cambronne XA, Cohen MS, Migaud ME, et al. Pharmacological bypass of NAD+ salvage pathway protects neurons from chemotherapy-induced degeneration. Proc Natl Acad Sci. 2018;115:10654-9. https://doi. org/10.1073/pnas.1809392115.

74. Bellampalli SS, Ji Y, Moutal A, Cai S, Wijeratne EMK, Gandini MA, et al. Betulinic acid, derived from the desert lavender Hyptis emoryi, attenuates paclitaxel-, HIV-, and nerve injury-associated peripheral sensory neuropathy via block of $\mathrm{N}$ - and T-type calcium channels. Pain. 2019;160:117-35. https://doi.org/10.1097/j. pain.0000000000001385.

75. Sittl R, Lampert A, Huth T, Schuy ET, Link AS, Fleckenstein J, et al. Anticancer drug oxaliplatin induces acute cooling-aggravated neuropathy via sodium channel subtype NaV1.6-resurgent and persistent current. Proc Natl Acad Sci. 2012;109:6704-9. https://doi.org/10.1073/pnas.1118058109.

76. Deuis JR, Zimmermann K, Romanovsky AA, Possani LD, Cabot PJ, Lewis RJ, et al. An animal model of oxaliplatin-induced cold allodynia reveals a crucial role for Nav1.6 in peripheral pain pathways. Pain. 2013;154:1749-57. https://doi.org/10.1016/j. pain.2013.05.032.

77. Furgała A, Fijałkowski Ł, Nowaczyk A, Sałat R, Sałat K. Timeshifted co-administration of sub-analgesic doses of ambroxol and pregabalin attenuates oxaliplatin-induced cold allodynia in mice. Biomed Pharmacother. 2018;106:930-40. https://doi. org/10.1016/j.biopha.2018.07.039.

78. Avan A, Postma TJ, Ceresa C, Avan A, Cavaletti G, Giovannetti E, et al. Platinum-induced neurotoxicity and preventive strategies: past, present, and future. Oncologist. 2015;20:411-32. https ://doi.org/10.1634/theoncologist.2014-0044.

79. Ibrahim S, Albany Z, Albany C. Significant response to lacosamide in a patient with severe chemotherapy-induced peripheral neuropathy. J Community Support Oncol. 2015;13:202-4. https ://doi.org/10.12788/jcso.0136.

80. Chang W, Berta T, Kim YH, Lee S, Lee S-Y, Ji R-R. Expression and role of voltage-gated sodium channels in human dorsal root ganglion neurons with special focus on Nav1.7, species differences, and regulation by paclitaxel. Neurosci Bull. 2018;34:4-12. https://doi.org/10.1007/s12264-017-0132-3.

81. Li Y, North RY, Rhines LD, Tatsui CE, Rao G, Edwards DD, et al. DRG voltage-gated sodium channel 1.7 is upregulated in paclitaxel-induced neuropathy in rats and in humans with neuropathic pain. J Neurosci. 2018;38:1124-36. https://doi. org/10.1523/JNEUROSCI.0899-17.2017.

82. Kerckhove N, Busserolles J, Stanbury T, Pereira B, Plence $\mathrm{V}$, Bonnetain $\mathrm{F}$, et al. Effectiveness assessment of riluzole in the prevention of oxaliplatin-induced peripheral neuropathy: 
RILUZOX-01: protocol of a randomised, parallel, controlled, double-blind and multicentre study by the UNICANCER-AFSOS Supportive Care intergroup. BMJ Open. 2019;9:e027770. https ://doi.org/10.1136/bmjopen-2018-027770.

83. Poupon L, Lamoine S, Pereira V, Barriere DA, Lolignier S, Giraudet F, et al. Targeting the TREK-1 potassium channel via riluzole to eliminate the neuropathic and depressive-like effects of oxaliplatin. Neuropharmacology. 2018;140:43-61. https://doi. org/10.1016/j.neuropharm.2018.07.026.

84. Anon B, Largeau B, Girault A, Chantome A, Caulet M, Perray $\mathrm{C}$, et al. Possible association of $\mathrm{CAG}$ repeat polymorphism in KCNN3 encoding the potassium channel SK3 with oxaliplatin-induced neurotoxicity. Cancer Chemother Pharmacol. 2018;82:149-57. https://doi.org/10.1007/s00280-018-3600-1.

85. Di Cesare ML, Lucarini E, Micheli L, Mosca I, Ambrosino P, Soldovieri MV, et al. Effects of natural and synthetic isothiocyanate-based $\mathrm{H} 2 \mathrm{~S}$-releasers against chemotherapy-induced neuropathic pain: Role of Kv7 potassium channels. Neuropharmacology. 2017;121:49-59. https://doi.org/10.1016/j.neuropharm .2017.04.029

86. Yamamoto K, Tsuboi M, Kambe T, Abe K, Nakatani Y, Kawakami K, et al. Oxaliplatin administration increases expression of the voltage-dependent calcium channel $\alpha_{2} \delta-1$ subunit in the rat spinal cord. J Pharmacol Sci. 2016;130:117-22. https:// doi.org/10.1016/j.jphs.2016.01.006.

87. Schmitt L-I, Leo M, Kleinschnitz C, Hagenacker T. Oxaliplatin modulates the characteristics of voltage-gated calcium channels and action potentials in small dorsal root ganglion neurons of rats. Mol Neurobiol. 2018;55:8842-55. https://doi.org/10.1007/ s12035-018-1029-5.

88. Leo M, Schmitt L-I, Jastrow H, Thomale J, Kleinschnitz C, Hagenacker T. Cisplatin alters the function and expression of N-type voltage-gated calcium channels in the absence of morphological damage of sensory neurons. Mol Pain. 2017;13:1744806917746565. https://doi.org/10.1177/17448 06917746565.

89. Sharma J, Maslov LN, Singh N, Jaggi AS. Pain attenuating actions of vincristinet-preconditioning in chemotherapeutic agent-induced neuropathic pain: key involvement of T-type calcium channels. Fundam Clin Pharmacol. 2019. https://doi. org/10.1111/fcp.12519.

90. Mizoguchi S, Andoh T, Yakura T, Kuraishi Y. Involvement of c-Myc-mediated transient receptor potential melastatin 8 expression in oxaliplatin-induced cold allodynia in mice. Pharmacol Reports. 2016;68:645-8. https://doi.org/10.1016/j.phare p.2016.03.001.

91. Nassini R, Gees M, Harrison S, De Siena G, Materazzi S, Moretto $\mathrm{N}$, et al. Oxaliplatin elicits mechanical and cold allodynia in rodents via TRPA1 receptor stimulation. Pain. 2011;152:162131. https://doi.org/10.1016/j.pain.2011.02.051.

92. Descoeur J, Pereira V, Pizzoccaro A, Francois A, Ling B, Maffre $\mathrm{V}$, et al. Oxaliplatin-induced cold hypersensitivity is due to remodelling of ion channel expression in nociceptors. EMBO Mol Med. 2011;3:266-78. https://doi.org/10.1002/emmm.20110 0134.

93. Boehmerle W, Huehnchen P, Lee SLL, Harms C, Endres M. TRPV4 inhibition prevents paclitaxel-induced neurotoxicity in preclinical models. Exp Neurol. 2018;306:64-75. https://doi. org/10.1016/J.EXPNEUROL.2018.04.014.

94. Materazzi S, Fusi C, Benemei S, Pedretti P, Patacchini R, Nilius B, et al. TRPA1 and TRPV4 mediate paclitaxel-induced peripheral neuropathy in mice via a glutathione-sensitive mechanism. Pflügers Arch Eur J Physiol. 2012;463:561-9. https://doi. org/10.1007/s00424-011-1071-x.

95. Alessandri-Haber N, Dina OA, Joseph EK, Reichling DB, Levine JD. Interaction of transient receptor potential vanilloid 4, integrin, and Src tyrosine kinase in mechanical hyperalgesia. J Neurosci. 2008;28:1046-57. https://doi.org/10.1523/JNEUR OSCI.4497-07.2008.

96. Miyake T, Nakamura S, Meng Z, Hamano S, Inoue K, Numata T, et al. Distinct mechanism of cysteine oxidation-dependent activation and cold sensitization of human transient receptor potential ankyrin 1 channel by high and low oxaliplatin. Front Physiol. 2017. https://doi.org/10.3389/fphys.2017.00878.

97. Sałat K, Filipek B. Antinociceptive activity of transient receptor potential channel TRPV1, TRPA1, and TRPM8 antagonists in neurogenic and neuropathic pain models in mice. J Zhejiang Univ B. 2015;16:167-78. https://doi.org/10.1631/jzus.B1400 189.

98. Boiko N, Medrano G, Montano E, Jiang N, Williams CR, Madungwe NB, et al. TrpA1 activation in peripheral sensory neurons underlies the ionic basis of pain hypersensitivity in response to vinca alkaloids. PLoS ONE. 2017;12:e0186888. https://doi.org/10.1371/journal.pone.0186888.

99. Tonello R, Fusi C, Materazzi S, Marone IM, De Logu F, Benemei $\mathrm{S}$, et al. The peptide Ph $\alpha 1 \beta$, from spider venom, acts as a TRPA1 channel antagonist with antinociceptive effects in mice. Br J Pharmacol. 2017;174:57-69. https://doi.org/10.1111/bph.13652.

100. Bobylev I, Elter T, Schneider C, Wunderlich G, Zimmer P, Streckmann F, et al. Chemotherapie-induzierte Polyneuropathie. Fortschritte Der Neurol Psychiatr. 2015;83:427-36. https://doi. org/10.1055/s-0035-1553475.

101. Xu J, Zhang L, Xie M, Li Y, Huang P, Saunders TL, et al. Role of complement in a rat model of paclitaxel-induced peripheral neuropathy. J Immunol. 2018;200:4094-101. https://doi. org/10.4049/jimmunol.1701716.

102. Starobova H, Mueller A, Deuis JR, Carter DA, Vetter I. Inflammatory and neuropathic gene expression signatures of chemotherapy-induced neuropathy induced by vincristine, cisplatin, and oxaliplatin in C57BL/6J mice. J Pain. 2019. https://doi. org/10.1016/j.jpain.2019.06.008.

103. Meregalli C, Marjanovic I, Scali C, Monza L, Spinoni N, Galliani $\mathrm{C}$, et al. High-dose intravenous immunoglobulins reduce nerve macrophage infiltration and the severity of bortezomibinduced peripheral neurotoxicity in rats. J Neuroinflammation. 2018;15:232. https://doi.org/10.1186/s12974-018-1270-x.

104. Guo R, Chen L-H, Xing C, Liu T. Pain regulation by gut microbiota: molecular mechanisms and therapeutic potential. Br J Anaesth. 2019;123:637-54. https://doi.org/10.1016/j. bja.2019.07.026.

105. Lees JG, Makker PGS, Tonkin RS, Abdulla M, Park SB, Goldstein D, et al. Immune-mediated processes implicated in chemotherapy-induced peripheral neuropathy. Eur J Cancer. 2017;73:22-9. https://doi.org/10.1016/j.ejca.2016.12.006.

106. Brandolini L, d'Angelo M, Antonosante A, Cimini A, Allegretti M. Chemokine signaling in chemotherapy-induced neuropathic pain. Int J Mol Sci. 2019;20:2904. https://doi.org/10.3390/ijms2 0122904.

107. Singhmar P, Huo X, Li Y, Dougherty PM, Mei F, Cheng X, et al. Orally active Epac inhibitor reverses mechanical allodynia and loss of intraepidermal nerve fibers in a mouse model of chemotherapy-induced peripheral neuropathy. Pain. 2018;159:884-93. https://doi.org/10.1097/j.pain.0000000000001160.

108. Brandolini L, Castelli V, Aramini A, Giorgio C, Bianchini G, Russo R, et al. DF2726A, a new IL-8 signalling inhibitor, is able to counteract chemotherapy-induced neuropathic pain. Sci Rep. 2019;9:11729. https://doi.org/10.1038/s41598-019-48231-z.

109. Makker PGS, Duffy SS, Lees JG, Perera CJ, Tonkin RS, Butovsky O, et al. Characterisation of immune and neuroinflammatory changes associated with chemotherapy-induced peripheral neuropathy. PLoS ONE. 2017. https://doi.org/10.1371/ JOURNAL.PONE.0170814. 
110. Zhong S, Zhou Z, Liang Y, Cheng X, Li Y, Teng W, et al. Targeting strategies for chemotherapy-induced peripheral neuropathy: does gut microbiota play a role? Crit Rev Microbiol. 2019;45:369-93. https://doi.org/10.1080/1040841X.2019.16089 05 .

111. Wang X-M, Lehky TJ, Brell JM, Dorsey SG. Discovering cytokines as targets for chemotherapy-induced painful peripheral neuropathy. Cytokine. 2012;59:3-9. https://doi.org/10.1016/j. cyto.2012.03.027.

112. Starkweather A. Increased interleukin-6 activity associated with painful chemotherapy-induced peripheral neuropathy in women after breast cancer treatment. Nurs Res Pract. 2010;2010:1-9. https://doi.org/10.1155/2010/281531.

113. Maruta T, Nemoto T, Hidaka K, Koshida T, Shirasaka T, Yanagita T, et al. Upregulation of ERK phosphorylation in rat dorsal root ganglion neurons contributes to oxaliplatin-induced chronic neuropathic pain. PLoS ONE. 2019;14:e0225586. https ://doi.org/10.1371/journal.pone.0225586.

114. Montague K, Malcangio M. The therapeutic potential of monocyte/macrophage manipulation in the treatment of chemotherapyinduced painful neuropathy. Front Mol Neurosci. 2017. https:// doi.org/10.3389/fnmol.2017.00397.

115. Zhou L, Ao L, Yan Y, Li W, Ye A, Hu Y, et al. The therapeutic potential of chemokines in the treatment of chemotherapyinduced peripheral neuropathy. Curr Drug Targets. 2019. https ://doi.org/10.2174/1389450120666190906153652.

116. Zhang H, Li Y, De Carvalho-Barbosa M, Kavelaars A, Heijnen CJ, Albrecht PJ, et al. Dorsal root ganglion infiltration by macrophages contributes to paclitaxel chemotherapy-induced peripheral neuropathy. J Pain. 2016. https://doi.org/10.1016/j. jpain.2016.02.011.

117. Illias AM, Gist AC, Zhang H, Kosturakis AK, Dougherty PM. Chemokine CCL2 and its receptor CCR2 in the dorsal root ganglion contribute to oxaliplatin-induced mechanical hypersensitivity. Pain. 2018;159:1308-16. https://doi.org/10.1097/j. pain.0000000000001212.

118. Montague K, Simeoli R, Valente J, Malcangio M. A novel interaction between CX3CR1 and CCR2 signalling in monocytes constitutes an underlying mechanism for persistent vincristineinduced pain. J Neuroinflammation. 2018;15:101. https://doi. org/10.1186/s12974-018-1116-6.

119. Jurga AM, Rojewska E, Piotrowska A, Makuch W, Pilat D, Przewlocka B, et al. Blockade of toll-like receptors (TLR2, TLR4) attenuates pain and potentiates buprenorphine analgesia in a rat neuropathic pain model. Neural Plast. 2016;2016:1-12. https:// doi.org/10.1155/2016/5238730.

120. Luo X, Huh Y, Bang S, He Q, Zhang L, Matsuda M, et al. Macrophage toll-like receptor 9 contributes to chemotherapy-induced neuropathic pain in male mice. J Neurosci. 2019;39:6848-64. https://doi.org/10.1523/JNEUROSCI.3257-18.2019.

121. Wanderley CW, Colon DF, Luiz JPM, Oliveira FF, Viacava PR, Leite CA, et al. Paclitaxel reduces tumor growth by reprogramming tumor-associated macrophages to an M1- profile in a TLR4-dependent manner. Cancer Res. 2018. https://doi. org/10.1158/0008-5472.CAN-17-3480.

122. Yan X, Maixner DW, Yadav R, Gao M, Li P, Bartlett MG, et al. Paclitaxel induces acute pain via directly activating toll like receptor 4. Mol Pain. 2015. https://doi.org/10.1186/s1299 0-015-0005-6.

123. Li Y, Adamek P, Zhang H, Tatsui CE, Rhines LD, Mrozkova P, et al. The cancer chemotherapeutic paclitaxel increases human and rodent sensory neuron responses to TRPV1 by activation of TLR4. J Neurosci. 2015;35:13487-500. https://doi.org/10.1523/ JNEUROSCI.1956-15.2015.
124. Gao D, Li W. Structures and recognition modes of toll-like receptors. Proteins Struct Funct Bioinforma. 2017;85:3-9. https://doi. org/10.1002/prot.25179.

125. Sootichote R, Thuwajit P, Singsuksawat E, Warnnissorn M, Yenchitsomanus $\mathrm{P}$, Ithimakin S, et al. Compound A attenuates toll-like receptor 4-mediated paclitaxel resistance in breast cancer and melanoma through suppression of IL-8. BMC Cancer. 2018;18:231. https://doi.org/10.1186/s12885-018-4155-6.

126. Gu H, Wang C, Li J, Yang Y, Sun W, Jiang C, et al. High mobility group box-1-toll-like receptor 4-phosphatidylinositol 3-kinase/ protein kinase B-mediated generation of matrix metalloproteinase-9 in the dorsal root ganglion promotes chemotherapyinduced peripheral neuropathy. Int J Cancer. 2019. https://doi. org/10.1002/ijc.32652.

127. Stojanovska V, McQuade RM, Fraser S, Prakash M, Gondalia $\mathrm{S}$, Stavely R, et al. Oxaliplatin-induced changes in microbiota, TLR4+ cells and enhanced HMGB1 expression in the murine colon. PLoS ONE. 2018;13:e0198359. https://doi.org/10.1371/ journal.pone.0198359.

128. El-Shitany NA, Eid B. Proanthocyanidin protects against cisplatin-induced oxidative liver damage through inhibition of

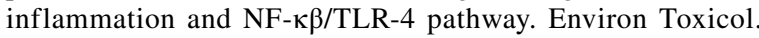
2017;32:1952-63. https://doi.org/10.1002/tox.22418.

129. Starobova H, Mueller A, Allavena R, Lohman RJ, Sweet MJ, Vetter I. Minocycline prevents the development of mechanical allodynia in mouse models of vincristine-induced peripheral neuropathy. Front Neurosci. 2019. https://doi.org/10.3389/fnins 2019.00653.

130. Ferrari LF, Araldi D, Green P, Levine JD. Marked sexual dimorphism in neuroendocrine mechanisms for the exacerbation of paclitaxel-induced painful peripheral neuropathy by stress. Pain. 2020. https://doi.org/10.1097/j.pain.0000000000001798.

131. Sorge RE, LaCroix-Fralish ML, Tuttle AH, Sotocinal SG, Austin J-S, Ritchie J, et al. Spinal cord toll-like receptor 4 mediates inflammatory and neuropathic hypersensitivity in male but not female mice. J Neurosci. 2011;31:15450-4. https://doi. org/10.1523/JNEUROSCI.3859-11.2011.

132. Krukowski K, Eijkelkamp N, Laumet G, Hack CE, Li Y, Dougherty PM, et al. CD8+ T cells and endogenous IL-10 are required for resolution of chemotherapy-induced neuropathic pain. J Neurosci. 2016;36:11074-83. https://doi.org/10.1523/JNEUR OSCI.3708-15.2016.

133. Laumet G, Edralin JD, Dantzer R, Heijnen CJ, Kavelaars A. Cisplatin educates CD8+ T cells to prevent and resolve chemotherapy-induced peripheral neuropathy in mice. Pain. 2019;160:1459-68. https://doi.org/10.1097/j.pain.0000000000 001512.

134. Ma J, Trinh RT, Mahant ID, Peng B, Matthias P, Heijnen CJ, et al. Cell-specific role of histone deacetylase 6 in chemotherapy-induced mechanical allodynia and loss of intraepidermal nerve fibers. Pain. 2019;160:2877-90. https://doi.org/10.1097/j. pain.0000000000001667.

135. Sekiguchi F, Domoto R, Nakashima K, Yamasoba D, Yamanishi $\mathrm{H}$, Tsubota M, et al. Paclitaxel-induced HMGB1 release from macrophages and its implication for peripheral neuropathy in mice: evidence for a neuroimmune crosstalk. Neuropharmacology. 2018;141:201-13. https://doi.org/10.1016/j.neuropharm .2018.08.040.

136. Shen S, Lim G, You Z, Ding W, Huang P, Ran C, et al. Gut microbiota is critical for the induction of chemotherapy-induced pain. Nat Neurosci. 2017;20:1213-6. https://doi.org/10.1038/ nn.4606.

137. Barragán-Iglesias P, Oidor-Chan VH, Loeza-Alcocer E, PinedaFarias JB, Velazquez-Lagunas I, Salinas-Abarca AB, et al. Evaluation of the neonatal streptozotocin model of diabetes in 
rats: evidence for a model of neuropathic pain. Pharmacol Rep. 2018;70:294-303. https://doi.org/10.1016/j.pharep.2017.09.002.

138. Ramakrishna C, Corleto J, Ruegger PM, Logan GD, Peacock $\mathrm{BB}$, Mendonca S, et al. Dominant role of the gut microbiota in chemotherapy induced neuropathic pain. Sci Rep. 2019;9:20324. https://doi.org/10.1038/s41598-019-56832-x.

139. Qin B, Luo N, Li Y, Gong D, Zheng J, Tan X, et al. Protective effect of gastrodin on peripheral neuropathy induced by antitumor treatment with vincristine in rat models. Drug Chem Toxicol. 2018. https://doi.org/10.1080/01480545.2018.1547739.

140. Yan X, Li F, Maixner DW, Yadav R, Gao M, Ali MW, et al. Interleukin-1beta released by microglia initiates the enhanced glutamatergic activity in the spinal dorsal horn during paclitaxelassociated acute pain syndrome. Glia. 2019;67:482-97. https:// doi.org/10.1002/glia.23557.

141. Wu J, Hocevar M, Bie B, Foss JF, Naguib M. Cannabinoid type 2 receptor system modulates paclitaxel-induced microglial dysregulation and central sensitization in rats. J Pain. 2019;20:501-14. https://doi.org/10.1016/j.jpain.2018.10.007.

142. Robinson CR, Zhang H, Dougherty PM. Astrocytes, but not microglia, are activated in oxaliplatin and bortezomib-induced peripheral neuropathy in the rat. Neuroscience. 2014;274:30817. https://doi.org/10.1016/j.neuroscience.2014.05.051.

143. Hu L-Y, Zhou Y, Cui W-Q, Hu X-M, Du L-X, Mi W-L, et al. Triggering receptor expressed on myeloid cells 2 (TREM2) dependent microglial activation promotes cisplatin-induced peripheral neuropathy in mice. Brain Behav Immun. 2018;68:132-45. https ://doi.org/10.1016/j.bbi.2017.10.011.

144. Reunanen J, Kainulainen V, Huuskonen L, Ottman N, Belzer $\mathrm{C}$, Huhtinen $\mathrm{H}$, et al. Akkermansia muciniphila adheres to enterocytes and strengthens the integrity of the epithelial cell layer. Appl Environ Microbiol. 2015. https://doi.org/10.1128/ AEM.04050-14.

145. Imai S, Koyanagi M, Azimi Z, Nakazato Y, Matsumoto M, Ogihara $\mathrm{T}$, et al. Taxanes and platinum derivatives impair Schwann cells via distinct mechanisms. Sci Rep. 2017;7:5947. https://doi. org/10.1038/s41598-017-05784-1.

146. Samineni VK, Premkumar LS, Faingold CL. Neuropathic paininduced enhancement of spontaneous and pain-evoked neuronal activity in the periaqueductal gray that is attenuated by gabapentin. Pain. 2017. https://doi.org/10.1097/j.pain.000000000000090 5.

147. Ferris CF, Nodine S, Pottala T, Cai X, Knox TM, Fofana FH, et al. Alterations in brain neurocircuitry following treatment with the chemotherapeutic agent paclitaxel in rats. Neurobiol Pain. 2019. https://doi.org/10.1016/j.ynpai.2019.100034.

148. Cavaletti G, Marmiroli P. Chemotherapy-induced peripheral neurotoxicity. Nat Rev Neurol. 2010. https://doi.org/10.1038/nrneu rol.2010.160.

149. Cata JP, Weng H-R, Chen J-H, Dougherty PM. Altered discharges of spinal wide dynamic range neurons and down-regulation of glutamate transporter expression in rats with paclitaxelinduced hyperalgesia. Neuroscience. 2006;138:329-38. https:// doi.org/10.1016/j.neuroscience.2005.11.009.

150. Boland EG, Selvarajah D, Hunter M, Ezaydi Y, Tesfaye S, Ahmedzai SH, et al. Central pain processing in chronic chemotherapy- induced peripheral neuropathy: a functional magnetic resonance imaging study. PLoS ONE. 2014. https://doi. org/10.1371/journal.pone.0096474.

151. Nudelman KNH, McDonald BC, Wang Y, Smith DJ, West JD, O'Neill DP, et al. Cerebral perfusion and gray matter changes associated with chemotherapy-induced peripheral neuropathy. J Clin Oncol. 2016. https://doi.org/10.1200/JCO.2015.62.1276.

152. Jaggi AS, Kaur G, Bali A, Singh N. Pharmacological investigations on mast cell stabilizer and histamine receptor antagonists in vincristine-induced neuropathic pain. Naunyn Schmiedebergs Arch Pharmacol. 2017;390:1087-96. https://doi.org/10.1007/ s00210-017-1426-8.

153. Boyette-Davis JA, Walters ET, Dougherty PM. Mechanisms involved in the development of chemotherapy-induced neuropathy. Pain Manag. 2015;5:285-96. https://doi.org/10.2217/ pmt.15.19.

154. Gao W, Zan Y, Wang ZJ, Hu X, Huang F. Quercetin ameliorates paclitaxel-induced neuropathic pain by stabilizing mast cells, and subsequently blocking PKC $\varepsilon$-dependent activation of TRPV1. Acta Pharmacol Sin. 2016;37:1166-77. https://doi.org/10.1038/ aps. 2016.58

155. Sałat K, Kołaczkowski M, Furgała A, Rojek A, Śniecikowska J, Varney MA, et al. Antinociceptive, antiallodynic and antihyperalgesic effects of the 5-HT 1A receptor selective agonist, NLX-112 in mouse models of pain. Neuropharmacology. 2017;125:181-8. https://doi.org/10.1016/j.neuropharm.2017.07.022.

156. Hache G, Guiard BP, Nguyen TH, Quesseveur G, Gardier AM, Peters D, et al. Antinociceptive activity of the new triple reuptake inhibitor NS18283 in a mouse model of chemotherapyinduced neuropathic pain. Eur J Pain. 2015;19:322-33. https:// doi.org/10.1002/ejp.550.

157. Potenzieri A, Riva B, Genazzani A. Unexpected Ca2+-mobilization of oxaliplatin via $\mathrm{H} 1$ histamine receptors. Cell Calcium. 2020;86:102128. https://doi.org/10.1016/J.CECA.2019.102128.

158. Kitamura R, Andoh T, Mizoguchi S, Saito Y, Takahata H, Kuraishi Y. Gabapentin inhibits bortezomib-induced mechanical allodynia through supraspinal action in mice. J Pharmacol Sci. 2014. https://doi.org/10.1254/jphs.13274FP.

159. Costa-Pereira JT, Serrão P, Martins I, Tavares I. Serotoninergic pain modulation from the rostral ventromedial medulla (RVM) in chemotherapy-induced neuropathy: the role of spinal 5-HT3 receptors. Eur J Neurosci. 2020;51:1756-69. https://doi. org/10.1111/ejn.14614.

160. Obata H. Analgesic mechanisms of antidepressants for neuropathic pain. Int J Mol Sci. 2017;18:2483. https://doi.org/10.3390/ ijms 18112483 .

161. Soni N, Reddy BVK, Kumar P. GLT-1 transporter: an effective pharmacological target for various neurological disorders. Pharmacol Biochem Behav. 2014;127:70-81. https://doi. org/10.1016/j.pbb.2014.10.001

162. Xu Y, Cheng G, Zhu Y, Zhang X, Pu S, Wu J, et al. Anti-nociceptive roles of the glia-specific metabolic inhibitor fluorocitrate in paclitaxel-evoked neuropathic pain. Acta Biochim Biophys Sin (Shanghai). 2016;48:902-8. https://doi.org/10.1093/abbs/gmw08 3.

163. Weng H-R, Aravindan N, Cata JP, Chen J-H, Shaw ADS, Dougherty PM. Spinal glial glutamate transporters downregulate in rats with taxol-induced hyperalgesia. Neurosci Lett. 2005;386:18-22. https://doi.org/10.1016/j.neulet.2005.05.049.

164. Yamamoto S, Ushio S, Egashira N, Kawashiri T, Mitsuyasu S, Higuchi $\mathrm{H}$, et al. Excessive spinal glutamate transmission is involved in oxaliplatin-induced mechanical allodynia: a possibility for riluzole as a prophylactic drug. Sci Rep. 2017;7:9661. https://doi.org/10.1038/s41598-017-08891-1.

165. Robinson CR, Dougherty PM. Spinal astrocyte gap junction and glutamate transporter expression contributes to a rat model of bortezomib-induced peripheral neuropathy. Neuroscience. 2015;285:1-10. https://doi.org/10.1016/j.neuroscien ce.2014.11.009.

166. Sałat K, Furgała A, Sałat R. Interventional and preventive effects of aripiprazole and ceftriaxone used alone or in combination on oxaliplatin-induced tactile and cold allodynia in mice. Biomed Pharmacother. 2019;111:882-90. https://doi.org/10.1016/j.bioph a.2019.01.008 
167. Krzyżanowska W, Pomierny B, Bystrowska B, PomiernyChamioło L, Filip M, Budziszewska B, et al. Ceftriaxone- and $\mathrm{N}$-acetylcysteine-induced brain tolerance to ischemia: Influence on glutamate levels in focal cerebral ischemia. PLoS ONE. 2017;12:e0186243. https://doi.org/10.1371/journal.pone.01862 43.

168. Niedzielska-Andres E, Mizera J, Sadakierska-Chudy A, Pomierny-Chamioło L, Filip M. Changes in the glutamate biomarker expression in rats vulnerable or resistant to the rewarding effects of cocaine and their reversal by ceftriaxone. Behav Brain Res. 2019;370:111945. https://doi.org/10.1016/j.bbr.2019.11194 5.

169. Bajrektarevic D, Nistri A. Ceftriaxone-mediated upregulation of the glutamate transporter GLT-1 contrasts neurotoxicity evoked by kainate in rat organotypic spinal cord cultures. Neurotoxicology. 2017;60:34-41. https://doi.org/10.1016/j.neuro .2017.02.013.

170. Hajhashemi V, Hosseinzadeh H, Amin B. Antiallodynia and antihyperalgesia effects of ceftriaxone in treatment of chronic neuropathic pain in rats. Acta Neuropsychiatr. 2013;25:27-322. https://doi.org/10.1111/j.1601-5215.2012.00656.x.

171. Luo H, Liu H-Z, Zhang W-W, Matsuda M, Lv N, Chen G, et al. Interleukin-17 regulates neuron-glial communications, synaptic transmission, and neuropathic pain after chemotherapy. Cell Rep. 2019;29:2384-97. https://doi.org/10.1016/j.celre p.2019.10.085(e5).

172. Sałat K, Kulig K, Sałat R, Filipek B, Malawska B. Analgesic and anticonvulsant activity of new derivatives of 2-substituted 4-hydroxybutanamides in mice. Pharmacol Rep. 2012;64:10212. https://doi.org/10.1016/S1734-1140(12)70736-3.

173. Masocha W, Parvathy SS. Preventative and therapeutic effects of a GABA transporter 1 inhibitor administered systemically in a mouse model of paclitaxel-induced neuropathic pain. PeerJ. 2016;4:e2798. https://doi.org/10.7717/peerj.2798.

174. Bráz JM, Wang X, Guan Z, Rubenstein JL, Basbaum AI. Transplant-mediated enhancement of spinal cord GABAergic inhibition reverses paclitaxel-induced mechanical and heat hypersensitivity. Pain. 2015;156:1084-91. https://doi.org/10.1097/j. pain.0000000000000152.

175. Yadav R, Yan X, Maixner DW, Gao M, Weng HR. Blocking the GABA transporter GAT-1 ameliorates spinal GABAergic disinhibition and neuropathic pain induced by paclitaxel. J Neurochem. 2015. https://doi.org/10.1111/jnc.13103.

176. Xu D, Zhao H, Gao H, Zhao H, Liu D, Li J. Participation of proinflammatory cytokines in neuropathic pain evoked by chemotherapeutic oxaliplatin via central GABAergic pathway. Mol
Pain. 2018;14:174480691878353. https://doi.org/10.1177/17448 06918783535.

177. Fijałkowski Ł, Sałat K, Podkowa A, Zaręba P, Nowaczyk A. Potential role of selected antiepileptics used in neuropathic pain as human GABA transporter isoform 1 (GAT1) inhibitorsmolecular docking and pharmacodynamic studies. Eur J Pharm Sci. 2017;96:362-72. https://doi.org/10.1016/j.ejps.2016.10.004.

178. Zaręba P, Gryzło B, Malawska K, Sałat K, Höfner GC, Nowaczyk A, et al. Novel mouse GABA uptake inhibitors with enhanced inhibitory activity toward mGAT3/4 and their effect on pain threshold in mice. Eur J Med Chem. 2020;188:111920. https:// doi.org/10.1016/J.EJMECH.2019.111920.

179. Craig AD. A rat is not a monkey is not a human: Comment on Mogil (Nature Rev. Neurosci. 10, 283-294 (2009)). Nat Rev Neurosci. 2009. https://doi.org/10.1038/nrn2606-c1.

180. Sorge RE, Mapplebeck JCS, Rosen S, Beggs S, Taves S, Alexander JK, et al. Different immune cells mediate mechanical pain hypersensitivity in male and female mice. Nat Neurosci. 2015. https://doi.org/10.1038/nn.4053.

181. Currie GL, Angel-Scott HN, Colvin L, Cramond F, Hair K, Khandoker L, et al. Animal models of chemotherapy-induced peripheral neuropathy: a machine-assisted systematic review and meta-analysis. PLoS Biol. 2019. https://doi.org/10.1371/journ al.pbio.3000243.

182. Mogil JS. Animal models of pain: progress and challenges. Nat Rev Neurosci. 2009. https://doi.org/10.1038/nrn2606.

183. Langford DJ, Crager SE, Shehzad Z, Smith SB, Sotocinal SG, Levenstadt JS, et al. Social modulation of pain as evidence for empathy in mice. Science (80-). 2006. https://doi.org/10.1126/ science. 1128322 .

184. Gadgil S, Ergün M, van den Heuvel SA, van der Wal SE, Scheffer GJ, Hooijmans CR. A systematic summary and comparison of animal models for chemotherapy induced (peripheral) neuropathy (CIPN). PLoS ONE. 2019. https://doi.org/10.1371/journ al.pone. 0221787 .

185. Dorsey SG, Kleckner IR, Barton D, Mustian K, O’Mara A, St. Germain D, et al. The national cancer institute clinical trials planning meeting for prevention and treatment of chemotherapy-induced peripheral neuropathy. JNCI J Natl Cancer Inst. 2019;111:531-7. https://doi.org/10.1093/jnci/djz011.

Publisher's Note Springer Nature remains neutral with regard to jurisdictional claims in published maps and institutional affiliations. 